\title{
On the Efficiency of Codeshare Contracts between Airlines: Is Double Marginalization Eliminated?
}

\author{
By Philip G. GAYLE*
}

\begin{abstract}
Previous research has suggested that codeshare agreements eliminate double marginalization that exists when unaffiliated airlines independently determine the price for different segments of an interline trip. Using a structural econometric model, this paper investigates whether codeshare contracts do eliminate double marginalization. The results suggest that both upstream and downstream margins persist when the operating carrier of a codeshare product also offers competing single-carrier product $(s)$ in the concerned market. Furthermore, counterfactual simulations from the model suggest that efficient pricing of these codeshare products would lower their price, and yield nontrivial increases in consumer welfare. (JEL D86, L13, L14, L93)
\end{abstract}

\begin{abstract}
Codesharing constitutes a contractual agreement among airlines that allows a carrier, called the "ticketing carrier," to market and sell seats on its partner's plane for segments of a route operated by its partner (the "operating carrier"). "Traditional" codeshare itineraries combine connecting operating services of partner carriers on a given route. For example, in traveling from Denver to Philadelphia, a passenger may buy the codeshare round-trip ticket from United Airlines, but the itinerary involves flying on a United-operated airplane from Denver to Boston, then connecting to a US Airways-operated airplane from Boston to Philadelphia.

Codesharing combines the operating services of at least two separate carriers. One of the carriers is responsible for marketing and sets the final price for the entire round-trip ticket, and compensates the other carrier for their operating services on a segment of the trip. It is reasonable to view codesharing as a vertical relationship between upstream and downstream firms. The pure operating carrier is equivalent to an upstream supplier that provides an essential input (operate a trip segment) to the downstream ticketing carrier, who then combines it with complementary trip segments in order to provide the final product to consumers..$^{1}$
\end{abstract}

\footnotetext{
* Department of Economics, 320 Waters Hall, Kansas State University, Manhattan, KS 66506 (e-mail: gaylep@ ksu.edu). I thank the editor, Robert Porter, and two anonymous referees for very helpful suggestions. I also benefited from invaluable suggestions and comments offered by Darin Lee, Jan Brueckner, Bryan Keating, John Crespi, and participants at the 9th International Industrial Organization Conference. I much appreciate timely inspiration provided by Alice Gayle and Kimani Gayle. Any remaining errors are my own.

${ }^{\dagger}$ Go to http://dx.doi.org/10.1257/mic.5.4.244 to visit the article page for additional materials and author disclosure statement(s) or to comment in the online discussion forum.

${ }^{1}$ Though not focussing on the economics of codesharing, Forbes and Lederman $(2009,2010)$ also view the relationship between major carriers and their regional feeder carriers in a vertical context.
} 
An often cited argument is that codesharing eliminates double marginalization that would otherwise exist when unaffiliated airlines independently determine the price for different segments of an interline trip (Brueckner, Lee, and Singer 2011; Brueckner and Proost 2010; Ito and Lee 2007; Brueckner and Whalen 2000; Brueckner 2001; Brueckner 2003; and Bamberger, Carlton, and Neumann 2004). The logic is that partners jointly price their codeshare products and therefore will price the trip segment (intermediate product) of any partner airline at the true marginal cost (Chen and Gayle 2007).

Chen and Gayle (2007) formally examine this pricing argument. In their theoretical analysis, double marginalization is not necessarily eliminated when partner airlines price their codeshare product. They study the equilibrium pricing incentives of partners in an alliance, and consider the endogenous formation of the alliance when multiple airlines can offer the intermediate flight. They find that codesharing may not eliminate double marginalization if a codeshare partner also offers a competing single-carrier product in the concerned market. If neither codeshare partner offers a competing single-carrier product, then codesharing does result in marginal cost pricing of the intermediate flight and lowers final prices.

The main contribution of this paper is to test Chen and Gayle (2007) theoretical prediction. I take the existing product set as given and estimate a structural econometric model of air travel demand and supply using data on US domestic air travel. The econometric model disentangles equilibrium final product prices into three components: (i) upstream margin; (ii) downstream margin; and (iii) marginal cost; which allows for a direct empirical test of whether double marginalization is eliminated. In the spirit of work by Villas-Boas (2007); Bonnet, Dubois, and Simioni (2006); Bonnet and Dubois (2010); and Bonnet, Dubois, and Villas-Boas (forthcoming), I use nonnested statistical tests for supply model selection to assess whether the data are consistent with a positive upstream margin for codeshare products in which a partner airline also offers a competing single-carrier product.

It is useful to describe why a codeshare agreement may not eliminate double marginalization. In the absence of an agreement between two carriers providing an interline trip, each carrier chooses its fare to maximize its own profit on the segment of the trip it operates. Neither carrier takes into account how its own pricing decision affects the profit of the complementary carrier (Brueckner 2003). Under a codeshare agreement, the carriers negotiate a pricing contract that can internalize the externality and maximize their joint profit. Therefore, it is natural to expect such agreements will eliminate double marginalization and result in efficient pricing. However, when the partners negotiate a price contract, if the upstream/pure operating carrier also offers its own competing single-carrier product, this carrier has an incentive to soften downstream competition for its own product by not eliminating the margin on its segment of the codeshare product.

Consistent with Chen and Gayle (2007), my econometric estimates suggest that the markup of the pure operating carrier is not eliminated when this partner carrier also offers a competing single-carrier product. This finding is important since the pure operating carrier offers competing single-carrier products for 81 percent of codeshare products. The empirical result may also be linked to the literature on vertical integration, which predicts that under some circumstances a vertically 
integrated firm, unlike an unintegrated firm, has an incentive to raise the input price to rival downstream firms to increase the competitive advantage of the downstream operations of the integrated firm (Hastings and Gilbert 2005; Chen 2001).

This is not the first paper to present evidence suggesting that double marginalization might not be eliminated from codeshare products. Ito and Lee (2007) find that traditional codeshare products are roughly 11.6 percent less expensive than interline products offered by nonallied carriers, but also that the codeshare products are 6.4 percent more expensive than single-carrier products in the same market. Single-carrier products by definition do not have double marginalization. If competing codeshare products also do not have double marginalization, their prices should not systematically differ from single-carrier products. One interpretation of Ito and Lee's (2007) finding is that double marginalization is not eliminated from traditional codeshare products. My analysis explicitly estimates the markups to directly test for elimination of double marginalization.

A useful feature of the structural econometric model is that counterfactual simulations can be performed to reveal how equilibrium prices, air travel demand, and consumer welfare are affected if codeshare products with double markup were efficiently priced. I artificially eliminate the upstream margin for these codeshare products in the sample to predict changes in equilibrium prices, air travel demand, and consumer surplus. I find that: (i) prices of these products decrease; (ii) number of passengers that purchase these products increase; and (iii) consumer surplus increase.

The rest of the paper is organized as follows. Definitions used throughout the paper are gathered in Section I. Section II describes the data used in estimation. Section III outlines the structural econometric model of air travel demand and supply. Estimation issues are discussed in Section IV. Results are discussed in Section V, and Section VI offers concluding remarks.

\section{Definitions}

A market is defined as directional round-trip air travel between an origin and destination city during a given time period. The assumption that markets are directional implies that round-trip air travel from Denver to Philadelphia is a distinct market as compared to round-trip air travel from Philadelphia to Denver. Furthermore, this directional assumption allows for the possibility that origin city characteristics may influence market demand.

A flight itinerary is defined as a specific sequence of airport stops in traveling from the origin to destination city. Products are defined as a unique combination of airline(s) and flight itinerary. An online product means that a passenger remains on a single carrier's network for all segments of a round trip. For example, three separate online products are: (i) a nonstop round trip from Denver to Philadelphia on US Airways; (ii) a round trip from Denver to Philadelphia with one stop in Charlotte on US Airways; and (iii) a nonstop round trip from Denver to Philadelphia on Northwest Airlines. Note that all three products are in the same market.

In contrast, for the type of codeshare products I focus on in this paper, referred to as "traditional" codeshare in the literature (see Ito and Lee 2007; and Gayle 2008), 


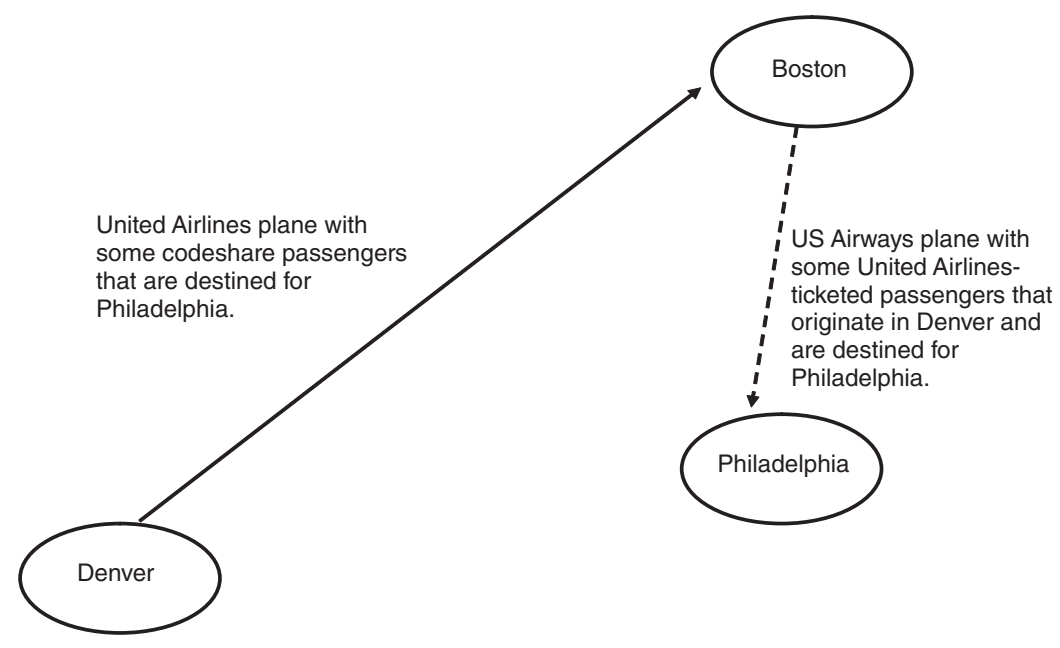

Figure 1. Route Network Diagram

passengers change airlines at least once on the round trip, but a single airline, normally referred to as the "ticketing carrier," is responsible for marketing and selling the ticket for the entire round trip. In addition, the ticketing carrier also provides operating services on at least one segment of the interline trip. The route network diagram in Figure 1 provides an example of a traditional codeshare product in the Denver to Philadelphia market. The codeshare product uses an interline itinerary between United Airlines and US Airways that has US Airways as a pure operating carrier on a trip segment, and United Airlines as the ticketing carrier. The passenger bought the round-trip ticket from United Airlines since United is the ticketing carrier for this codeshare product. However, the product's itinerary requires the passenger to first fly on a United Airlines-operated plane from Denver to Boston, then connect to a US Airways-operated plane from Boston to Philadelphia.

There are cases in which codeshare itineraries only involve a single operating carrier for the entire trip even though the ticket for the trip was marketed and sold by a partner carrier. Such itineraries are referred to as "virtual" codesharing; but unlike "traditional" codesharing, it is argued that airlines' incentive to offer virtual codeshare tickets is not related to their desire to eliminate double marginalization. As such, this paper focuses on traditional codesharing, and in what follows, codesharing should be interpreted in the traditional context. Ito and Lee (2007) provide detail discussions of virtual codesharing versus traditional codesharing and airlines' incentives for engaging in each type of codesharing (also see Gayle 2008, 2007b; and Gayle and Xie 2012).2

Throughout the paper, "upstream" and "downstream" carriers do not correspond to which plane a codeshare passenger boards first on the interline itinerary. Upstream carrier simply means the pure operating carrier, which could be the

\footnotetext{
${ }^{2}$ Gayle and Xie (2012) investigate the relative importance of traditional codesharing versus virtual codesharing in deterring market entry of potential competitors.
} 
operating carrier for any segment of the interline trip, while the downstream carrier is the ticketing carrier that also operates a segment of the trip, which could be the first segment. We can therefore think of the pure operating carrier as equivalent to an upstream supplier that provides an essential input (operate a trip segment) to the downstream carrier who then combines it with other inputs (complementary trip segments) in order to provide the final product to consumers. As such, in the example above, US Airways is the upstream carrier, while United Airlines is the downstream carrier.

I label a codeshare product and the upstream carrier of the codeshare product as "integrated" if the upstream carrier simultaneously offers competing online product(s) in the same market, otherwise the codeshare product and the upstream carrier are labeled as "unintegrated." In Figure 1, the codeshare product and US Airways are considered unintegrated since US Airways does not offer an online product in the Denver to Philadelphia market. However, consider a situation in which US Airways also offers its own nonstop product between Denver and Philadelphia. In that case, the one-stop codeshare product between United Airlines and US Airways is an imperfect substitute for the nonstop online product offered by US Airways. As such, both products compete with each other and the codeshare product along with US Airways are considered integrated.

\section{Data}

The data are drawn from the Origin and Destination Survey (DB1B), which is a 10 percent random sample of airline tickets from reporting carriers. This database is maintained and published by the US Bureau of Transportation Statistics. Some of the items included in DB1B are: (i) the number of passengers that choose a given flight itinerary; (ii) the fares of these itineraries; (iii) the specific sequence of airport stops that each itinerary uses in getting passengers from the origin to destination city; (iv) the carrier that marketed and sold the travel ticket (ticketing carriers), and the carrier(s) that passengers actually fly on for their trip (operating carriers); and (v) the distance flown on each itinerary in a directional market. The distance associated with each itinerary in a market may differ since each itinerary may use different connecting airports in transporting passengers from the origin to destination city. Unfortunately, there is no passenger-specific information in the data, nor is there any information on ticket restrictions such as advance-purchase and length-of-stay requirements. The frequency of the data are quarterly. For this research, I focus on the US domestic market in 2006 from quarter one to quarter four.

To construct the sample for estimation, I first drop itineraries with price less than $\$ 100$ due to the high probability that these may be coding errors. In addition, this restriction helps to eliminate discounted fares that may be due to passengers using frequent-flyer miles to partly pay for the product. The data are then collapsed by averaging the price and aggregating the number of passengers purchasing products as defined by itinerary-airline(s) combination. In other words, before the data are collapsed, there are several observations of a given itinerary-airline(s) combination that are distinguished by prices paid and number of passengers paying each of those prices. 
Table 1-Summary Statistics on Market Characteristics for In-Sample and Out-of-Sample Markets

\begin{tabular}{|c|c|c|c|}
\hline & $\begin{array}{l}\text { In-sample } \\
\text { markets }\end{array}$ & $\begin{array}{l}\text { Out-of-sample } \\
\text { markets }\end{array}$ & \\
\hline & $\begin{array}{c}\text { Mean } \\
\text { (standard error) }\end{array}$ & $\begin{array}{c}\text { Mean } \\
\text { (standard error) }\end{array}$ & $\begin{array}{c}\text { Difference in } \\
\text { means } \\
\text { (standard error) }\end{array}$ \\
\hline Market origin city population & $\begin{array}{l}1,614,770 \\
(156,274.80)\end{array}$ & $\begin{array}{l}852,015.10 \\
(44,562.07)\end{array}$ & $\begin{array}{l}762,754.90 * * * \\
(162,504.10)\end{array}$ \\
\hline Market nonstop flight distance (miles) & $\begin{array}{r}2,111.95 \\
(29.21)\end{array}$ & $\begin{array}{r}1,771.33 \\
(29.31)\end{array}$ & $\begin{array}{l}340.62 * * * \\
(41.38)\end{array}$ \\
\hline Number of substitute products per market & $\begin{array}{l}17.84 \\
(0.316)\end{array}$ & $\begin{array}{l}10.05 \\
(0.292)\end{array}$ & $\begin{array}{l}7.79 * * * \\
(0.43)\end{array}$ \\
\hline Number of traditional codeshare products per market & $\begin{array}{l}2.96 \\
(0.096)\end{array}$ & 0 & - \\
\hline Number of competing carriers per market & $\begin{array}{l}8.65 \\
(0.117)\end{array}$ & $\begin{array}{l}5.91 \\
(0.118)\end{array}$ & $\begin{array}{l}2.74 * * * \\
(0.17)\end{array}$ \\
\hline Number of markets & 220 & 361 & \\
\hline
\end{tabular}

Note: Standard errors are in parentheses.

*** Significant at the 1 percent level.

** Significant at the 5 percent level.

* Significant at the 10 percent level.

The data are further pruned based on several restrictions. First, I select products that were bought by at least ten passengers during a given quarter, and markets that have at least ten products with at least one of these products being a traditional codeshare product. Berry (1992) and Aguirregabiria and Ho (2012) among others use similar, and sometimes more stringent, number of passengers threshold to help eliminate idiosyncratic product offerings that are not part of the normal set of products offered in a market. Since the focus of this paper is on traditional codesharing between airlines, and traditional codeshare products are not nearly as popular as online products (see Ito and Lee 2007), the data sample needs to have markets that contain sufficient traditional codeshare products to facilitate proper econometric identification of codesharing effects. This explains the requirement that each sample market has at least one traditional codeshare product.

Table 1 reports summary data for market characteristics on markets that remained in the sample_- "in-sample" markets - compared to characteristics of markets that do not have any codeshare products, and therefore did not survive the pruning process used to construct the working data sample- - out-of-sample" markets. The table shows that market characteristics, as measured by origin city population, nonstop flight distance, number of substitute products per market, and number of competing carriers per market, are all larger in magnitude for in-sample markets compared to out-of-sample markets. The difference in means of each measured market characteristic across in-sample versus out-of-sample markets is statistically significant at conventional levels of statistical significance. In summary, we can conclude that, relative to out-of-sample markets, in-sample markets are: (i) larger in terms of potential passengers; (ii) require longer travel distances; and (iii) more competitive in terms of number of substitute products, and number of competing carriers. 
A second sample restriction is that I focus on traditional codeshare and online products as defined previously. Thus, I do not consider complicated products where a subset of the trip segments are codeshared while other segments are operated by unaffiliated carriers. Third, I follow the standard practice for empirical analyses of airline codesharing, and recode regional feeder carriers to have their major carrier codes. This paper, like much of the literature on airline codesharing, focuses on codesharing between major carriers. Therefore, if I did not recode feeder carriers, then products that only include a major carrier and its associated regional feeder carrier(s) may "mistakenly" be counted as codeshare products since the operating and ticketing carrier codes would differ. For example, American Eagle (MQ) is a regional feeder carrier for American Airlines (AA), a major carrier. So a product that is purchased from $\mathrm{AA}$, but has an itinerary that requires the passenger to fly on MQ for a segment of the trip, will be mistakenly classified as a codeshare product if I do not recode the MQ flight to have the AA code. The resulting sample used in estimation covers 220 markets and has 3,924 observations/products.

Product characteristics that influence consumers' air travel demand are captured using the following variables: "Price," "Hub," "Inconvenient," "Hub $\times$ Inconvenient," and "Codeshare," while ticketing carrier] dummy variables are used to control for a portion of unobserved product characteristics, and time dummies are used to control for seasonal demand effects. "Price" is the mean fare of a given itinerary-airline(s) combination; "Hub" is a zero-one dummy variable that takes the value one only if the origin airport is a hub for the ticketing carrier; "Inconvenient" is the ratio of itinerary distance to the nonstop distance between the origin and destination airports; "Hub $\times$ Inconvenient" is the interaction of "Hub" and "Inconvenient"; and "Codeshare" is a dummy variable taking the value one if the product is codeshared, and zero otherwise. An itinerary is presumed to be less convenient the larger is its "Inconvenient" measure. The minimum value that "Inconvenient" can take is one, which occurs when an itinerary uses a single nonstop flight between the origin and destination city.

Some defining characteristics of the data are as follows: 16.59 percent of the products are codeshared, while the remaining products are online. For 81.41 percent of the codeshare products, the upstream carrier/pure operating carrier also offers their own competing online products in the same market. Jet fuel price is an average 192.43 cents per gallon over the sample period, ranging from 175.48 to 206.81 cents per gallon. ${ }^{4}$ Additional summary statistics are reported in Table 2 In Appendix A, a list of the airlines in the sample are reported in Table A1; and a list of the cities, states, and corresponding airports in the data sample are reported in Table A2

\footnotetext{
${ }^{3}$ I use ticketing carrier dummies rather than operating carrier dummies in the demand model since it is the ticketing carrier that interacts with the consumer in the marketing and selling of a codeshare product. The issue of ticketing versus operating carrier does not arise for online products since a single carrier performs both roles for the entire itinerary.

${ }^{4}$ The data source for jet fuel price is: US Energy Information Administration: Official Energy Statistics from the US Government.
} 
Table 2-Summary Statistics

\begin{tabular}{lcccc}
\hline \hline & \multicolumn{3}{c}{ Codeshare products } \\
\cline { 2 - 5 } Variable & Mean & Standard deviation & Min. & Max. \\
\cline { 2 - 5 } Price $(\$)$ & 237.15 & 64.77 & 123.11 & 685.04 \\
Hub & 0.23 & 0.42 & 0 & 1 \\
Inconvenient & 1.114 & 0.13 & 1.0004 & 1.525 \\
Itinerary distance (miles) & $2,369.46$ & 488.19 & 1,005 & 3,565 \\
& & & & \\
Price (\$) & & Online products & \\
Hub & 236.55 & 64.59 & 0 & 1 \\
Inconvenient & 0.10 & 0.30 & 1 & 1.909 \\
Itinerary distance (miles) & 1.087 & 0.106 & 3,695 \\
\hline
\end{tabular}

\section{The Model}

I now outline a model of air travel demand and supply. I begin with the demand side, which is modeled within a discrete choice framework. Specifically, I use a random coefficients logit demand model. I then outline the supply side of the model, which is where the vertical contracting is captured. It must be noted however that the empirical model assumes that the existing menu of products offered in a market, and firms' choice of whether to form a codeshare alliance, are predetermined at the time of optimal price-setting behavior. Since the focus of this paper is on optimal price-setting behavior conditional on the menu of products that already exists in the market, a more general model in which codeshare alliance formation is endogenous is beyond the scope of this paper and left for future research.

\section{A. Demand}

Potential passenger $i$ in market $t$ faces a choice between $J_{t}+1$ alternatives. There are $J_{t}+1$ alternatives because I allow passengers the option $(j=0)$ not to choose one of the $J_{t}$ differentiated air travel products considered in the empirical model. A passenger chooses the product that gives him the highest utility; that is

$$
\max _{j \in\left\{0, \ldots, J_{t}\right\}}\left\{U_{i j t}=\mathbf{x}_{j t} \boldsymbol{\beta}_{i}+\alpha_{i} p_{j t}+a_{j}+\xi_{j t}+\varepsilon_{i j t}\right\},
$$

where $U_{i j t}$ is the value of product $j$ to passenger $i$; $\mathbf{x}_{j t}$ is a vector of observed nonprice product characteristics (a measure of itinerary convenience, a zero-one indicator variable that takes the value one only if the origin is a hub for the carrier that offers the product for sale, a zero-one indicator variable that takes the value one only if the product is codeshare, and time dummy variables); $\boldsymbol{\beta}_{i}$ is a vector of consumerspecific marginal utilities (assumed random) associated with the different nonprice product characteristics in $\mathbf{x}_{j t} ; p_{j t}$ is the price that a consumer must pay to consume product $j ; \alpha_{i}$ represents consumer-specific marginal utility of price (also assumed random across consumers); $a_{j}$ are firm fixed effects (ticketing carrier dummy 
variables) capturing characteristics of the products that are the same across markets and time; $\xi_{j t}$ is a measure of differences in product quality that are unobserved by the researcher, but observed by consumers and firms; and $\varepsilon_{i j t}$ is a mean-zero random component of utility.

Following much of the discrete choice demand literature (see Nevo 2000a), $\varepsilon_{i j t}$ is assumed to be governed by an independent and identically distributed extreme value density. The probability that product $j$ is chosen, or equivalently the predicted (by the model) market share of product $j$ is

$$
d_{j t}\left(\mathbf{x}_{j t}, p_{j t} ; \alpha, \boldsymbol{\beta}, \boldsymbol{\sigma}\right)=\int \frac{e^{\delta_{j t}+\mu_{i j t}}}{1+\sum_{l=1}^{J} e^{\delta_{l t}+\mu_{i l t}}} d F(\boldsymbol{\nu}),
$$

where $\delta_{j t}=\mathbf{x}_{j t} \boldsymbol{\beta}+\alpha p_{j t}+a_{j}+\xi_{j t}$ is the mean utility (across consumers) obtained from consuming product $j$; and $\mu_{i j t}=\sigma_{p} p_{j t} v_{i p}+\sum_{k=1}^{K} \sigma_{k} x_{j t k} v_{i k}$ is a consumer-specific deviation from the mean utility level which depends on the consumers' taste for each product characteristic, where $\sigma=\left(\sigma_{p}, \sigma_{1}, \ldots, \sigma_{K}\right)$ is a set of parameters that measure variation (across consumers) in random taste shocks for respective product characteristics, and $\mathbf{v}_{i}=\left(v_{i p}, v_{i 1}, \ldots, v_{i K}\right)$ is a set of consumer $i^{\prime} s$ random taste shocks for respective product characteristics. $F(\cdot)$ is the standard normal distribution function that governs the taste shocks. As is well known in the empirical industrial organization literature, there is no closed-form solution for the integral in equation $(2)$, and thus it must be approximated numerically using random draws from $F(\nu) .5$

Given market size of measure $M_{t}$, which I assume to be the size of the population in the origin city, observed share of product $j$ in market $t$ is $D_{j t}=\frac{q_{j t}}{M_{t}}$, where $q_{j t}$ is the actual number of travel tickets sold for a particular itinerary-airline(s) combination called product $j$. The observed market share for each product is computed analogously. In Appendix C, I describe how observed and predicted product shares are used in estimation.

\section{B. Supply}

In this subsection, I derive a supply equation that approximates airlines' optimizing behavior for each type of product supplied (codeshare and online). To the best of my knowledge, this paper constitutes the first attempt to use a structural econometric model designed to explicitly capture the optimizing behavior to supply codeshare products. ${ }^{6}$ In the spirit of Villas-Boas (2007 and 2009); Bonnet, Dubois, and Villas-Boas (forthcoming); Bonnet, Dubois, and Simioni (2006); and Bonnet and

\footnotetext{
${ }^{5}$ I use 200 random draws from $F(\cdot)$ for the numerical approximation of $d_{j t}(\cdot)$.

${ }^{6}$ Armantier and Richard (2008) use a structural econometric model to analyze the consumer welfare consequences of codeshare alliances. However, their model focuses on the demand side of the market and does not explicitly considers the optimizing behavior of airlines in supplying codeshare products.
} 
Dubois (2010), behavioral equations are derived that express price-cost margins as a function of demand parameters.

Codeshare Products. - We may think of a codeshare agreement as a privately negotiated pricing contract between partners $(s, \Upsilon)$, where $s$ is a per-passenger price the ticketing carrier pays to a pure operating carrier for its services needed to complete the trip, while $\Upsilon$ represents a potential fixed transfer between the partners that determines how the joint surplus is distributed. In what follows, only the level of $s$ affects equilibrium final product prices. The equilibrium value of $\Upsilon$ depends on specific assumptions about the bargaining process. However, for purposes of this paper I am not concerned how the surplus is distributed between partners through the fixed transfer $\Upsilon$.

The modeling approach described above is a simplification of codeshare agreements since airlines may actually use more complicated mechanisms to compensate each other on codeshare flights. While some information is available on compensation mechanisms used between major carriers and their regional feeder partners (see Forbes and Lederman 2013), the focus of the present paper is codesharing between major carriers. Specific codeshare compensation mechanisms between major partner airlines are not usually made known to the public, and may even vary across partnerships. The extent of what is commonly known is that the ticketing carrier markets and sets the final price for the round-trip ticket, and compensates the pure operating carrier for operating services provided on complementary trip segments. Therefore, the simplistic modeling approach of using $(s, \Upsilon)$ to represent a codeshare contract captures our basic understanding of what is commonly known without imposing too much structure on a contracting process about which we have few facts.

To obtain an empirical model that allows for double marginalization, I assume that the prices of codeshare products are determined within a sequential price-setting game. In this game the upstream carrier (pure operating carrier) first sets the price for its segment of the trip, $s$, then the downstream carrier (ticketing carrier) sets the final round-trip price, $p$, given the agreed-upon price for the services supplied by an upstream carrier. To solve for the subgame perfect Nash equilibrium in sequential games, it is standard to start by looking at the final subgame in the sequential game. The final subgame in this vertical model is a Bertrand-Nash game between downstream carriers.

In what follows, I suppress the market index $t$ only to avoid a clutter of subscripts. Therefore, when I specify an airline's profit function, it represents the airline's profit only in market $t$.

Let $r=1, \ldots, R$ index ticketing carriers that compete in a downstream market, and let $f=1, \ldots, F$ index the corresponding upstream carriers. Further, let $\mathcal{F}_{r}$ be a subset of the $J$ codeshare products that are offered for sale by ticketing carrier $r$. Thus, carriers are allowed to offer multiple products for sale. Ticketing carrier $r$ solves the following optimization problem:

$$
\max _{p_{j}}\left\{\sum_{j \in \mathcal{F}_{r}}\left(p_{j}-s_{j}^{f}-c_{j}^{r}\right) M \cdot d_{j}(\mathbf{p})\right\},
$$


where $d_{j}(\mathbf{p})$ is the predicted market share function for product $j ; \mathbf{p}$ represents a vector of final prices; $c_{j}^{r}$ is the constant marginal cost carrier $r$ incurs in providing the services necessary to offer product $j$; and as defined previously, $s_{j}^{f}$ is the price the ticketing carrier pays to pure operating carrier $f$ for its services needed to complete the trip.

The first-order conditions generated from the optimization problem in (3) are a set of $J$ equations, one for each product. Following expositions in Nevo (2000b) and Villas-Boas (2007), the set of $J$ first-order conditions imply the following product markup equation expressed in matrix notation:

$$
\mathbf{p}-\mathbf{s}^{f}-\mathbf{c}^{r}=-\left(\Omega_{r} \times \Delta_{r}\right)^{-1} \mathbf{d}(\mathbf{p}),
$$

where $\mathbf{d}(\cdot), \mathbf{p}, \mathbf{s}^{f}$, and $\mathbf{c}^{r}$ are $J \times 1$ vectors of product shares, final prices, upstream carriers' prices, and downstream carriers' marginal costs, respectively; $\Omega_{r}$ is a $J \times J$ matrix of appropriately positioned zeros and ones based on the ticketing carriers' ownership structure of the $J$ products; $\Delta_{r}$ is a $J \times J$ matrix of first-order derivatives of predicted product shares with respect to final prices; and $\Omega_{r} \times \Delta_{r}$ is an elementby-element multiplication of the two matrices.

Having characterized the price-cost markup behavior of downstream carriers, as captured by equation (4), I now turn to the problem of the upstream carriers. Let $\mathcal{S}_{f}$ be a subset of the $J$ products to which carrier $f$ supply pure operating services. Again, I allow carriers to offer pure operating services to multiple products. Given that final prices are a function of upstream prices via equation (4), then predicted product shares are also a function of upstream prices: $d_{j}\left(\mathbf{p}\left(\mathbf{s}^{f}\right)\right)$.

Knowing that ticketing carriers behave according to equation (4), each upstream carrier solves the following problem:

$$
\max _{s_{j}^{f}}\left\{\sum_{j \in \mathcal{S}_{f}}\left(s_{j}^{f}-c_{j}^{f}\right) M \cdot d_{j}\left(\mathbf{p}\left(\mathbf{s}^{f}\right)\right)\right\}
$$

where $c_{j}^{f}$ is the marginal cost that carrier $f$ incurs when providing pure operating services to product $j$. The system of $J$ first-order conditions generated from the optimization problem in (5) imply the following markup equation:

$$
\mathbf{s}^{f}-\mathbf{c}^{f}=-\left(\Omega_{f} \times \Delta_{f}\right)^{-1} \mathbf{d}(\mathbf{p}),
$$

where $\mathbf{c}^{f}$ is a $J \times 1$ vector of pure operating carriers' marginal cost; $\Omega_{f}$ is a $J \times J$ matrix of appropriately positioned zeros and ones based on upstream carriers' ownership structure of the $J$ products; and $\Delta_{f}$ is a $J \times J$ matrix of derivatives of predicted product shares with respect to upstream carrier prices. In Appendix B I discuss how $\Delta_{f}$ is computed. Note that $\Omega_{f} \neq \Omega_{r}$, since subsets of the $J$ competing products owned by ticketing and pure operating carriers may differ.

Finally, to derive an expression for the overall price-cost margin for codeshare products, I sum equations (4) and (6), which yields:

$$
\mathbf{p}-\mathbf{c}^{r}-\mathbf{c}^{f}=-\left(\Omega_{r} \times \Delta_{r}\right)^{-1} \mathbf{d}(\mathbf{p})-\left(\Omega_{f} \times \Delta_{f}\right)^{-1} \mathbf{d}(\mathbf{p}) .
$$


Note that equation (7) has the useful property that estimation of overall pricecost margins does not require information on prices that pure operating carriers charge their partner ticketing carrier, i.e., the researcher does not need to know $\mathbf{s}^{f}$. This property is useful since data on the prices that airlines use as a basis for trading services among themselves are difficult to obtain.

Online Products.- - In presenting the vertical pricing model above, it is implicitly assumed that all $J$ products in the market are supplied using a codeshare structure. However, in a more realistic setting a subset of the $J$ products are likely to be online products. This can be captured in the model above by assuming that online products represent cases where the downstream and upstream carriers are vertically integrated. Such vertical integration serves to eliminate the upstream markup and therefore $s_{k}^{f}=c_{k}^{f}$ for any online product $k$. As such, in modifying the supply model to capture cases where some products are online, the downstream markup equation (equation (4)) is unchanged and apply to all products, while the new upstream equation for codeshare products is

$$
\mathbf{S}^{f}-\mathbf{c}^{f}=-\left(\boldsymbol{\Omega}_{f}^{\text {code }} \times \Delta_{f}^{\text {code }}\right)^{-1} \mathbf{d}(\mathbf{p})^{\text {code }},
$$

where $\Omega_{f}^{\text {code }}$ and $\Delta_{f}^{\text {code }}$ are square matrices containing the rows and columns of $\boldsymbol{\Omega}_{f}$ and $\Delta_{f}$ that correspond to codeshare products, and $\mathbf{d}(\mathbf{p})^{\text {code }}$ is a vector containing predicted market shares of codeshare products in $\mathbf{d}(\mathbf{p})$. Thus, the overall price-cost margin for each codeshare product is given by the upstream markup, captured in equation (8), plus the corresponding downstream markup, captured by equation (4), while online products only have a downstream markup.

A Unified Supply Equation.-Let $\mathbf{m}_{d}$ and $\mathbf{m}_{u}$ be $J \times 1$ vectors containing downstream and upstream margins, respectively. Note that the margin functions depend on prices and demand parameters: $\mathbf{m}_{d}(\mathbf{p} ; \alpha, \boldsymbol{\beta}, \boldsymbol{\sigma})$ and $\mathbf{m}_{u}(\mathbf{p} ; \alpha, \boldsymbol{\beta}, \boldsymbol{\sigma})$. However, in much of what follows I simply use $\mathbf{m}_{d}$ and $\mathbf{m}_{u}$ only for notational convenience. For example, overall price-cost margins in a market containing both types of products are given by

$$
\mathbf{p}-\mathbf{c}^{T}=\mathbf{m}_{d}+\mathbf{m}_{u},
$$

where $\mathbf{c}^{T}$ is a $J \times 1$ vector containing aggregate marginal costs for supplying each product. Equation (9) can also be expressed as

$$
\mathbf{p}=\mathbf{c}^{T}+\mathbf{m}_{d}+\mathbf{m}_{u} \text {. }
$$

Alternate Supply Equation Specifications.-Let the marginal cost function be specified as

$$
\mathbf{c}^{T}=\exp (\mathbf{W} \gamma+\psi)
$$


where $W$ is a vector of variables that shift marginal cost (itinerary distance, itinerary distance squared, time dummies, jet fuel price interacted with operating carrier dummies); $\gamma$ is a vector of estimable parameters in the marginal cost function; and $\psi$ is the portion of marginal cost that is unobserved by the researcher, which I assume to be a random term with zero mean. The specification of the marginal cost function in equation (11) is admittedly simplistic since it does not allow for endogenous aspects of airlines costs such as density economies. However, a more general specification that allows for density economies will make post-estimation counterfactual analysis infeasible. As such, following Berry and Jia (2010), I chose to use a restrictive specification of marginal cost that buys me the benefit of being able to use the estimated model for counterfactual simulations.

As previously defined, a codeshare product and the upstream carrier of the codeshare product is considered "integrated" if the upstream carrier simultaneously offers competing online product(s) in the same market, otherwise the codeshare product and the upstream carrier are considered as "unintegrated." Based on theoretical predictions in Chen and Gayle (2007), optimal price-setting behavior of codeshare partners will eliminate the upstream margin for unintegrated products, but not eliminate the upstream margin for integrated codeshare products. Therefore, based on equations (10) and (11), the true parametric supply equation specification, which I define as Model 1, is given by

$$
\text { Model 1: } \mathbf{p}=\exp (\mathbf{W} \boldsymbol{\gamma}+\boldsymbol{\psi})+\mathbf{m}_{d}^{1}+\mathbf{m}_{u}^{1},
$$

where the positive elements in the $J \times 1$ vector $\mathbf{m}_{u}^{1}$ are for integrated codeshare products, while the remaining elements are zeros for online and unintegrated codeshare products. In other words, Model 1 allows an upstream margin only for integrated codeshare products.

In the event that codeshare partners' optimal price-setting behavior is consistent with predictions in Chen and Gayle (2007), then Model 1 should provide a better statistical fit of the data compared to the following alternate specifications:

$$
\begin{aligned}
& \text { Model 2: } \mathbf{p}=\exp (\mathbf{W} \boldsymbol{\gamma}+\boldsymbol{\psi})+\mathbf{m}_{d}^{2}+\mathbf{m}_{u}^{2}, \\
& \text { Model 3: } \mathbf{p}=\exp (\mathbf{W} \boldsymbol{\gamma}+\boldsymbol{\psi})+\mathbf{m}_{d}^{3}, \\
& \text { Model 4: } \mathbf{p}=\exp (\mathbf{W} \boldsymbol{\gamma}+\boldsymbol{\psi})+\mathbf{m}_{d}^{4}+\mathbf{m}_{u}^{4} .
\end{aligned}
$$

Model 2 assumes the upstream margin is not eliminated from codeshare products, whether they be of the integrated type or not. As such, the positive elements in the $J \times 1$ vector $\mathbf{m}_{u}^{2}$ are for all codeshare products, while the remaining elements are zeros for online products. Model 3 assumes that the upstream margin is eliminated for both integrated and unintegrated codeshare products, therefore no upstream margin term is needed in this specification. Last, Model 4 assumes an upstream margin exists only for unintegrated codeshare products, i.e., the positive elements in the $J \times 1$ vector $\mathbf{m}_{u}^{4}$ are for unintegrated codeshare products, while the remaining elements are zeros for online and integrated codeshare products. 
In what follows, I jointly estimate demand and marginal cost parameters under each alternate supply equation specification and use nonnested statistical tests based on Rivers and Vuong (2002) and Smith (1992) to see which specification best fits the data. ${ }^{7}$ One reason I estimate the demand parameters jointly with marginal cost parameters is that Gayle (2007a) shows, in the case of airline data, information from the supply side of the market significantly helps in obtaining demand parameter estimates that are consistent with static profit maximization. In the case of the automobile industry, Berry, Levinsohn, and Pakes (1995) also find that joint estimation of demand and supply sides of the model significantly improves demand estimates.

\section{Estimation}

The demand and marginal cost parameters are estimated jointly using Generalized Methods of Moments (GMM). Estimation details are provided in Appendix C.

Since it is reasonable to assume that airlines take into account changes in unobserved (to the researcher) product quality, $\xi_{j t}$, when setting prices, then prices will depend on $\xi_{j t}$. As such, the estimated coefficient on price will be inconsistent if appropriate instruments are not found for prices. Following much of the literature on discrete choice models of demand, one identifying assumption I make is that observed nonprice product characteristics in $x_{j t}$ are uncorrelated with changes in the unobserved product quality, $\xi_{j t}$. Since airline dummy variables are included in the mean utility function, it is only changes in the portion of product quality not specific to airlines that is captured in $\xi_{j t}$. Hence, this identifying assumption seems reasonable. 8

Similar to Villas-Boas (2007), I also exploit the time dimension of the data to construct instruments for airline ticket price in the demand equation. In particular, I observe variations in jet fuel price over the time span of the data, and therefore make the identifying assumption that changes in jet fuel price is likely to affect airlines' marginal cost differently. The reason for the assumed differential effect on marginal cost is that airlines differ in their route network structure and size distribution of their aircraft fleet. In addition, it is reasonable to assume that airlines do not routinely change their aircraft fleet with each change in jet fuel price. As such, airlines are likely to differ in the intensity with which they use fuel. Given that an airline's marginal cost is correlated with its price, and I assume that shocks to fuel price are uncorrelated with $\xi_{j t}$, then the interaction of fuel price with operating carrier(s) dummies are valid instruments for airline ticket price. In addition, since the marginal cost of servicing an itinerary is assumed to be a positive function of itinerary distance, itinerary distance is also used as an instrument for airline ticket price.

In summary, the demand instruments include: (i) interaction of fuel price with operating carrier(s) dummies; (ii) itinerary distance; (iii) the squared deviation of a product's itinerary distance from the average itinerary distance of competing

\footnotetext{
${ }^{7}$ Since demand and marginal cost parameters are jointly estimated, the pair of estimated margins $\left(\mathbf{m}_{d}\right.$ and $\left.\mathbf{m}_{u}\right)$ are different under each alternate supply equation specification, as such, the competing estimated supply equations are not nested.

${ }^{8}$ See Berry and Jia (2010); Berry, Carnall, and Spiller (2006); Nevo (2000a); Villas-Boas (2007); and Goldberg and Verboven (2001) for similar identifying assumptions.
} 
products offered by other airlines; and (iv) an airline's market mean itinerary inconvenient measure, i.e., market mean, by airline, of the variable "Inconvenient"-a nonprice product characteristic measure previously discussed in the data section. ${ }^{9}$ All these instruments are motivated by supply theory, which predicts that equilibrium price is affected by changes in marginal cost and changes in markup.

Instruments (iii) and (iv) are assumed to influence the size of an airline's markup on each of its products. Instrument (iii) is a measure of how closely substitutable an airline's product is relative to its competitors' products. The smaller is the deviation of a product's itinerary distance from other products in the same market, the closer a substitute the product is for competing products, and the smaller is the markup that an airline is able to charge on the product. Instrument (iv) captures the average convenience of flight itineraries offered by an airline in the relevant market. The greater is the airline's mean itinerary inconvenient measure, the lower is the markup the airline is able to charge on products, ceteris paribus.

Even though it is reasonable and correct to argue that instruments (iii) and (iv) are strategic choices of an airline and therefore they are not strictly exogenous, their validity relies on the assumption that these strategic choices are made prior to the realization of unobserved shocks to demand or marginal cost, $\left(\xi_{j t}, \psi_{j t}\right)$. This is an admittedly strong assumption, but it is typical in the literature as better alternatives are difficult to find.

Recall that the error term in the supply equation, $\psi_{j t}$, captures unobserved (by the researcher) determinants of marginal cost, which in turn influences equilibrium prices. As such, the margin terms, $m_{d j t}$ and $m_{u j t}$, are likely to be correlated with $\psi_{j t}$ in the supply equation. Based on the discussion of the validity of instruments used in the demand equation, instruments (iii) and (iv) above are also valid for the supply equation. ${ }^{10}$

\section{Results}

I begin by estimating a standard logit specification of the demand model, which is more restrictive than the demand model outlined previously in the sense that the standard logit does not allow marginal utilities for product characteristics to vary across consumers. Estimates from the standard logit specification are not reported here but are available upon request. The estimates reveal significant difference in the ordinary least squares (OLS) price coefficient estimate compared to the twostage least squares (2SLS) price coefficient estimate, which is suggestive that the endogeneity of price indeed results in severe bias of the price coefficient estimate if instruments are not used for price. The Wu-Hausman test easily rejects that price is exogenous at conventional levels of significance. First-stage regression estimates, also available upon request, in which price is regressed on the instruments has $R^{2}=0.28$. An $F$-test of the joint statistical significance of the instruments in the first-stage regression yields: $F(30,3871)=14.12$; and a $p$-value for the $F$-statistic

\footnotetext{
${ }^{9}$ Interactions of some of these variables are also included as instruments.

${ }^{10}$ Since itinerary distance is included in the marginal cost function, it cannot instrument for the margin terms in the supply equation.
} 
of 0.000 , which suggest that the instruments do have explanatory power of variations in price.

I now focus the remainder of the discussion on estimates from the less restrictive random coefficients logit demand model. Table 3 reports both demand and marginal cost parameter estimates under each of the alternate supply equation specifications (Model 1; Model 2; Model 3; and Model 4 ) previously discussed. The upper panel of the table reports the mean marginal (dis)utility for each product characteristic ( $\alpha$ and $\boldsymbol{\beta}$ ), while the panel immediately below this upper panel reports the parameter estimates that measure variation in taste for each product characteristic $(\boldsymbol{\sigma})$. As expected, the price coefficient estimate suggest that, on average, passengers are less likely to choose a flight itinerary the higher its price, ceteris paribus.

It has been suggested that owing to frequent-flyer programs, hub airlines might have more brand-loyal customers at their hub airports (Berry, Carnall, and Spiller 2006). In addition, airlines tend to offer more convenient flight itineraries and more flight options out of their hub airports. ${ }^{11}$ These arguments are consistent with the positive coefficient on "Hub" even though here it is not statistically significant at conventional levels of significance.

The coefficient on "Inconvenient" is not statistically significant at conventional levels of significance, but as expected and suggested by its negative sign, passengers seem to prefer itineraries that are more convenient and use a less circuitous route in traveling from the origin to destination city (Gayle 2007a). The coefficient on the interaction between "Inconvenient" and "Hub" is negative as expected. The negative coefficient on this interaction variable suggests that the marginal disutility associated with itinerary inconvenience is greater for hub products compared to nonhub products. A plausible interpretation of this result is that passengers expect hub products to have convenient routing, and thus these products are more heavily penalized relative to nonhub products for not having convenient routing.

The coefficient on the codeshare dummy is not statistically significant at conventional levels of statistical significance, but its consistent negative sign across all specifications suggests that passengers may perceive traditional codeshare products as an inferior substitute to online products. Since a codeshare product requires that the passenger changes airlines on a given trip, one explanation for this choice behavior of passengers is that partner airlines have not been able to make passengers transition across airlines seamless, thus resulting in traditional codeshare products' being inferior substitutes for online products.

The coefficients on the time period dummies do suggest the presence of seasonality in air travel demand. In particular, air travel demand seems to be highest in spring and summer, which accords with our expectations.

The taste variation parameters that are statistically significant at conventional levels of significance suggest that passengers are heterogenous, with respect to their taste, for these measured product characteristics in the model. This result provides reassurance that the less restrictive random coefficients logit model is likely a more accurate description of air travel demand compared to the standard logit model.

\footnotetext{
${ }^{11}$ For more discussion on airlines market power and demand advantages at their hub airports see Borenstein (1989, 1991); Berry (1990); Evans and Kessides (1993); and Lederman (2007).
} 
Table 3-Estimates from Joint Estimation of Demand and Marginal Cost Parameters, when Demand Is Based on the Random CoEfFicients Logit SPECIFICATION

\begin{tabular}{|c|c|c|c|c|c|c|c|c|}
\hline \multirow[b]{2}{*}{ Means, $(\alpha, \boldsymbol{\beta})$} & \multicolumn{2}{|c|}{$\begin{array}{c}\text { Supply equation allows } \\
\text { upstream margin only } \\
\text { on integrated codeshare } \\
\text { products } \\
\text { (Model 1) }\end{array}$} & \multicolumn{2}{|c|}{$\begin{array}{c}\text { Supply equation } \\
\text { allows upstream } \\
\text { margin on all } \\
\text { codeshare products } \\
\text { (Model 2) }\end{array}$} & \multicolumn{2}{|c|}{$\begin{array}{c}\text { Supply equation does } \\
\text { not allow upstream mar- } \\
\text { gin on any codeshare } \\
\text { product } \\
\text { (Model 3) }\end{array}$} & \multicolumn{2}{|c|}{$\begin{array}{c}\text { Supply equation allows } \\
\text { upstream margin only } \\
\text { on unintegrated code- } \\
\text { share products } \\
\text { (Model 4) }\end{array}$} \\
\hline & $\begin{array}{l}\text { Parameter } \\
\text { estimates }\end{array}$ & $\begin{array}{c}\text { Standard } \\
\text { errors }\end{array}$ & $\begin{array}{l}\text { Parameter } \\
\text { estimates }\end{array}$ & $\begin{array}{c}\text { Standard } \\
\text { errors }\end{array}$ & $\begin{array}{l}\text { Parameter } \\
\text { estimates }\end{array}$ & $\begin{array}{l}\text { Standard } \\
\text { errors }\end{array}$ & $\begin{array}{l}\text { Parameter } \\
\text { estimates }\end{array}$ & $\begin{array}{c}\text { Standard } \\
\text { errors }\end{array}$ \\
\hline Constant & $-6.438 * *$ & 0.9864 & $-6.467 * *$ & 1.0800 & $-6.442 * *$ & 1.0450 & $-6.451 * *$ & 0.9830 \\
\hline Price (Thousands, \$) & $-26.377 * *$ & 7.2138 & $-25.920 * *$ & 7.6184 & $-26.236^{* *}$ & 7.5331 & $-26.406 * *$ & 7.2360 \\
\hline Hub & 2.294 & 1.7469 & 2.277 & 1.6991 & 2.252 & 1.7219 & 2.284 & 1.7468 \\
\hline Inconvenient & -0.696 & 0.9375 & -0.690 & 1.0574 & -0.685 & 0.9930 & -0.663 & 0.9165 \\
\hline Hub $\times$ Inconvenient & $-2.030 * *$ & 0.9138 & $-2.092 * *$ & 0.9453 & $-2.069 * *$ & 0.9387 & $-2.028 * *$ & 0.9147 \\
\hline Codeshare & -4.215 & 2.7307 & -3.773 & 2.9083 & -3.908 & 2.8419 & -4.274 & 2.6996 \\
\hline Quarter 1-Winter & $-0.150 *$ & 0.0899 & $-0.150 *$ & 0.0899 & $-0.151 *$ & 0.0899 & $-0.149 *$ & 0.0898 \\
\hline Quarter 2-Spring & $0.277 * *$ & 0.0899 & $0.272 * *$ & 0.0903 & $0.273 * *$ & 0.0897 & $0.278^{* *}$ & 0.0900 \\
\hline Quarter 3-Summer & $0.305^{* *}$ & 0.0914 & $0.309 * *$ & 0.0926 & $0.306 * *$ & 0.0921 & $0.305^{* *}$ & 0.0917 \\
\hline \multicolumn{9}{|l|}{ Taste variation, $(\boldsymbol{\sigma})$} \\
\hline Constant & -0.238 & 0.7888 & -0.083 & 0.9108 & -0.157 & 0.8609 & -0.237 & 0.7841 \\
\hline Price (thousands, \$) & $-5.349 *$ & 2.7591 & $-5.221 *$ & 3.0191 & $-5.325^{*}$ & 2.9198 & $-5.351^{*}$ & 2.7601 \\
\hline Hub & 1.243 & 1.1987 & 1.312 & 1.1690 & 1.315 & 1.1800 & 1.252 & 1.1940 \\
\hline Inconvenient & $0.897 *$ & 0.5015 & 0.883 & 0.5699 & $0.884 *$ & 0.5349 & $0.879 *$ & 0.4993 \\
\hline Codeshare & $-2.745^{* *}$ & 1.3651 & $-2.515^{*}$ & 1.4858 & $-2.588^{*}$ & 1.4451 & $-2.773 * *$ & 1.3436 \\
\hline \multicolumn{9}{|l|}{ Marginal cost, $(\gamma)$} \\
\hline Constant & $-2.035^{* *}$ & 0.0925 & $-2.017 * *$ & 0.0921 & $-1.982 * *$ & 0.0812 & $-1.961 * *$ & 0.0781 \\
\hline Itinerary distance & 0.984 & 0.6721 & 0.776 & 0.6876 & 0.635 & 0.6075 & 0.458 & 0.6221 \\
\hline$(\text { Itinerary distance })^{2}$ & 1.640 & 1.5071 & 2.136 & 1.5743 & 2.253 & 1.4125 & $2.661 *$ & 1.4823 \\
\hline Quarter 1-Winter & $-0.027 * *$ & 0.0116 & $-0.031 * *$ & 0.0121 & $-0.034 * *$ & 0.0112 & $-0.037 * *$ & 0.0115 \\
\hline Quarter 2-Spring & $0.075^{* *}$ & 0.0127 & $0.077 * *$ & 0.0127 & $0.064 * *$ & 0.0115 & $0.066 * *$ & 0.0116 \\
\hline Quarter 3-Summer & $0.068 * *$ & 0.0144 & $0.069 * *$ & 0.0145 & $0.055^{* *}$ & 0.0125 & $0.055^{* *}$ & 0.0126 \\
\hline $\begin{array}{l}\text { Value of GMM objective } \\
\text { from joint estimation }\end{array}$ & \multicolumn{2}{|c|}{0.0738196} & \multicolumn{2}{|c|}{0.0738448} & \multicolumn{2}{|c|}{0.0738362} & \multicolumn{2}{|c|}{0.0738804} \\
\hline $\begin{array}{l}\text { Post-estimation } \\
\text { computation of GMM } \\
\text { objective function } \\
\text { value for supply } \\
\text { equation }\end{array}$ & \multicolumn{2}{|c|}{0.0045} & \multicolumn{2}{|c|}{0.0046} & \multicolumn{2}{|c|}{0.0056} & \multicolumn{2}{|c|}{0.0053} \\
\hline
\end{tabular}

Notes: Ticketing carrier dummy variables are included in the demand model even though these coefficient estimates are not reported. Similarly, the interactions of jet fuel price with operating carrier(s) dummies are included in the marginal cost function even though these coefficient estimates are not reported.

*** Significant at the 1 percent level.

** Significant at the 5 percent level.

* Significant at the 10 percent level.

The demand parameter estimates across the four alternate models in Table 3 yield a mean own-price elasticity of demand of -4.72 . Peters (2006) found mean own-price elasticity estimates ranging from -3.2 to -4.0 depending on the type of discrete choice demand model used (nested logit or generalized extreme value $(\mathrm{GEV})$ ). One possible reason the estimated own-price elasticities in this paper is on the higher end of the spectrum is because the data sample likely contain a higher proportion of traditional codeshare products compared to data samples in most other airline studies. Recall that in the data section I stated that a criterion for a market to remain in the final sample is that it contains at least ten products with at least one of these products being a traditional codeshare product. Since traditional codesharing 
tends to lower prices, ${ }^{12}$ it is reasonable to conjecture that competition may be stiffer, markups lower, and own-price elasticities higher, in markets with a higher prevalence of traditional codeshare products.

The positive coefficient on itinerary distance suggests that marginal cost may be increasing in itinerary distance, but the distance coefficients are estimated with some noise. However, the robustly estimated coefficients on the seasonal dummies in the marginal cost equation suggest that marginal cost of providing air travel is highest in spring and summer. These marginal cost parameter estimates accord with what we would expect since longer travel distances require more fuel, and with peak travel season being in the summer, fuel price is likely to be highest at that time of year.

\section{A. Statistical Nonnested Tests for Model Selection}

While the qualitative results across the four alternate model specifications are similar, as suggested by the coefficient estimates in Table 3, we have not yet resolved which specification provides the best statistical fit of the data. For this analysis I rely on a nonnested statistical test in Rivers and Vuong (2002) and Smith (1992).13

The test statistic used to statistically compare the alternate supply specifications is given by

$$
T=\frac{\sqrt{n}}{\hat{w}}\left[G M M_{i}-G M M_{j}\right], \quad \text { for } i \neq j,
$$

where $G M M_{i}$ is the value of the GMM objective function for supply Model $i$; GMM is the value of the GMM objective function for supply Model $j$; and $\hat{w}$ is an estimate of the standard error of the difference in the GMM objective function value of supply Model $i$ and supply Model $j$. The last row of Table 3 reports post-estimation computation of the GMM objective function value for each of the alternate supply equation specifications. Test statistic $T$ is normally distributed. The null hypothesis is that the two models being compared by the test are asymptotically equivalent. As such, for this one tail test at a 5 percent level of significance, $T>1.64$ implies that supply Model $i$ is statistically inferior to supply Model $j$ (for $i \neq j$ and $i, j=1,2,3,4$ ), $T<-1.64$ implies that supply Model $j$ is statistically inferior to supply Model $i$, while $-1.64<T<1.64$ implies that we cannot statistically distinguish between the two models being compared.

Table 4 reports computed values for test statistic $T$ for pairwise comparisons of the alternate supply specifications. The computed values in the table reveal that supply Models 1 and 2 each statistically fit the data better when compared to supply Model 3, i.e., where $T=10.79$ and $T=13.99$, respectively, in Table 4. In other words, the evidence suggest that a supply model which eliminates upstream margin on codeshare products is statistically inferior to supply models that allow upstream

\footnotetext{
${ }^{12}$ See Brueckner, Lee, and Singer (2011); Brueckner and Proost (2010); Ito and Lee (2007); Brueckner and Whalen, (2000); Brueckner (2001); Brueckner (2003).

${ }^{13}$ This nonnested test is also used by Bonnet, Dubois, and Villas-Boas (forthcoming) and Villas-Boas (2007) for supply model selection, similar to how I am using the test.
} 
Table 4-Nonnested Tests for Model Selection

\begin{tabular}{lcc}
\hline \hline & $\begin{array}{c}\text { Model 1: Supply equation } \\
\text { allows upstream margin only on } \\
\text { integrated codeshare products }\end{array}$ & $\begin{array}{c}\text { Model 3: Supply equation does } \\
\text { not allow upstream margin on } \\
\text { any codeshare product }\end{array}$ \\
\hline $\begin{array}{l}\text { Model 2: Supply equation allows } \\
\text { upstream margin on all codeshare } \\
\text { products }\end{array}$ & $\begin{aligned} T & =\hat{w}^{-1} \sqrt{n}\left[G M M_{2}-G M M_{1}\right] \\
& =0.70\end{aligned}$ & $\begin{array}{r}T=\hat{w}^{-1} \sqrt{n}\left[G M M_{3}-G M M_{2}\right] \\
=13.99\end{array}$ \\
$\begin{array}{l}\text { Model 3: Supply equation does } \\
\text { not allow upstream margin on any } \\
\text { codeshare product }\end{array}$ & $\begin{aligned} T \\
\text { Model 4: Supply equation allows } \\
\text { upstream margin only on unintegrated } \\
\text { codeshare products }\end{aligned}$ & $=10.79$
\end{tabular}

Notes: Table reports values of the nonnested test statistic $T=\hat{w}^{-1} \sqrt{n}\left[G M M_{i}-G M M_{j}\right]$ for the pair wise comparisons of respective supply models. The test statistic is normally distributed. As such, for these one tale tests at a 5 percent level of significance, if $T>1.64$ supply Model $i$ is statistically inferior to supply Model $j$ (for $i \neq j$ and $i, j=1,2,3,4)$; while if $T<-1.64$, then supply Model $j$ is statistically inferior to supply Model $i$. Last, if $-1.64<T<1.64$, then supply Models $i$ and $j$ are statistically indistinguishable.

margin on these products. The positive nonnested test statistic value in the table when comparing supply Models 1 and 2 suggests that Model 1 may better fit the data compared to Model 2. However, since the actual test statistic value, $T=0.70$, is less than 1.64, this suggests that the "margin" of superiority of Model 1 over 2 is not statistically significant at conventional levels of statistical significance.

Recall that the vast majority of codeshare products (81.41 percent in the sample) are of the integrated type. Therefore, it is possible that the sample split between integrated and unintegrated codeshare products is not sufficiently equitable to generate enough statistical power to distinguish between supply Models 1 and 2. Fortunately, we can still get at the issue of which type of codeshare product is more likely to have an upstream margin. To assess this issue I use the nonnested test to compare supply Models 1 and 4, i.e., I compare a supply model that allows an upstream margin only on integrated codeshare products (Model 1) to a supply model that allows an upstream margin only on unintegrated codeshare products (Model 4). The value of the nonnested test statistic when Models 1 and 4 are compared is $T=8.69$, suggesting that the supply model which allows an upstream margin only on integrated codeshare products is statistically superior to a supply model that allows an upstream margin only on unintegrated codeshare products.

In summary, results from the nonnested statistical tests are consistent with what is theoretically predicted in Chen and Gayle (2007). The idea is that the strategic incentives of an upstream/pure operating carrier of a traditional codeshare product who also offers its own online product in the said market (integrated upstream carrier) is likely to differ from an upstream carrier that does not offer its own competing online product (unintegrated upstream carrier). Specifically, the integrated upstream carrier optimally chooses not to eliminate its margin for its codeshare products. A reason for such strategic behavior by the integrated upstream carrier is that by raising the price of its trip segment (the intermediate good price), this carrier is able to reduce the intensity of downstream competition for its own online product. As such, even when codeshare partners negotiate a pricing contract that maximizes their joint 
Table 5-Price-Cost Margins and Recovered Marginal Cost, by Airline, For Integrated CODEShare Products

\begin{tabular}{|c|c|c|c|c|c|c|c|c|c|}
\hline \multirow[b]{2}{*}{ Airline name } & \multicolumn{2}{|c|}{$\begin{array}{l}\text { Downstream } \\
\text { carrier } \\
\text { margin }\end{array}$} & \multicolumn{2}{|c|}{$\begin{array}{c}\text { Upstream } \\
\text { carrier } \\
\text { margin }\end{array}$} & \multicolumn{2}{|c|}{$\begin{array}{c}\text { Total } \\
\text { margin }\end{array}$} & \multicolumn{2}{|c|}{$\begin{array}{l}\text { Recovered } \\
\text { marginal } \\
\text { cost }\end{array}$} & \multirow[t]{2}{*}{$\begin{array}{c}\text { Number } \\
\text { of } \\
\text { products }\end{array}$} \\
\hline & $\begin{array}{l}\text { Mean } \\
\text { levels } \\
(\$)\end{array}$ & $\begin{array}{c}\text { Mean } \\
\text { percent } \\
\text { of price } \\
(\%)\end{array}$ & $\begin{array}{l}\text { Mean } \\
\text { levels } \\
(\$)\end{array}$ & $\begin{array}{l}\text { Mean } \\
\text { percent } \\
\text { of price } \\
(\%)\end{array}$ & $\begin{array}{l}\text { Mean } \\
\text { levels } \\
(\$)\end{array}$ & $\begin{array}{l}\text { of price } \\
\text { (Lerner } \\
\text { index) } \\
(\%)\end{array}$ & $\begin{array}{l}\text { Mean } \\
\text { levels } \\
(\$)\end{array}$ & $\begin{array}{c}\text { Mean } \\
\text { percent } \\
\text { of price } \\
(\%)\end{array}$ & \\
\hline American Airlines Inc. & $\begin{array}{l}46.53 * * * \\
(0.748)\end{array}$ & $\begin{array}{l}18.64 * * * * \\
(0.508)\end{array}$ & $\begin{array}{l}44.77 * * * \\
(0.666)\end{array}$ & $\begin{array}{l}17.94 * * * \\
(0.478)\end{array}$ & $\begin{array}{l}91.30 * * * \\
(1.407)\end{array}$ & $\begin{array}{l}36.58 * * * \\
(0.985)\end{array}$ & $\begin{array}{c}172.05 * * * \\
(8.184)\end{array}$ & $\begin{array}{l}\text { 63.42*** } \\
(0.985)\end{array}$ & 80 \\
\hline Alaska Airlines Inc. & $\begin{array}{l}46.94 * * * \\
(0.883)\end{array}$ & $\begin{array}{l}20.95 * * * \\
(0.609)\end{array}$ & $\begin{array}{l}44.40 * * * \\
(0.700)\end{array}$ & $\begin{array}{l}19.77 * * * \\
(0.502)\end{array}$ & $\begin{array}{l}91.34 * * * \\
(1.559)\end{array}$ & $\begin{array}{l}40.72 * * * \\
(1.103)\end{array}$ & $\begin{array}{c}140.71 \text { *** } \\
(6.371)\end{array}$ & $\begin{array}{l}59.28 * * * \\
(1.103)\end{array}$ & 56 \\
\hline America West Airlines & $\begin{array}{l}46.67 * * * \\
(0.611)\end{array}$ & $\begin{array}{l}21.06 * * * \\
(0.368)\end{array}$ & $\begin{array}{l}45.10 * * * \\
(0.555)\end{array}$ & $\begin{array}{l}20.37 * * * \\
(0.358)\end{array}$ & $\begin{array}{l}91.77 * * * \\
(1.156)\end{array}$ & $\begin{array}{l}41.43 * * * \\
(0.723)\end{array}$ & $\begin{array}{c}134.78^{* * * *} \\
(4.126)\end{array}$ & $\begin{array}{l}58.57 * * * \\
(0.723)\end{array}$ & 95 \\
\hline United Air Lines Inc. & $\begin{array}{l}48.56 * * * \\
(0.662)\end{array}$ & $\begin{array}{l}20.55 * * * \\
(0.435)\end{array}$ & $\begin{array}{l}46.40 * * * \\
(0.587)\end{array}$ & $\begin{array}{l}19.70 * * * \\
(0.431)\end{array}$ & $\begin{array}{l}94.97 * * * \\
(1.232)\end{array}$ & $\begin{array}{l}40.26 * * * \\
(0.862)\end{array}$ & $\begin{array}{c}155.20 * * * \\
(6.983)\end{array}$ & $\begin{array}{l}59.74 * * * \\
(0.862)\end{array}$ & 107 \\
\hline US Airways Inc. & $\begin{array}{l}48.27 * * * \\
(0.523)\end{array}$ & $\begin{array}{l}18.82 * * * \\
(0.313)\end{array}$ & $\begin{array}{l}46.29 * * * \\
(0.482)\end{array}$ & $\begin{array}{l}18.06 * * * * \\
(0.301)\end{array}$ & $\begin{array}{l}94.57 * * * \\
(0.998)\end{array}$ & $\begin{array}{l}36.88 * * * \\
(0.612)\end{array}$ & $\begin{array}{c}172.22 * * * \\
(5.047)\end{array}$ & $\begin{array}{l}63.12 * * * \\
(0.612)\end{array}$ & 149 \\
\hline Southwest Airlines & $\begin{array}{l}44.58 * * * \\
(1.080)\end{array}$ & $\begin{array}{l}21.89 * * * \\
(0.618)\end{array}$ & $\begin{array}{l}42.70^{* * * *} \\
(0.956)\end{array}$ & $\begin{array}{l}20.98 * * * \\
(0.563)\end{array}$ & $\begin{array}{l}87.28 * * * \\
(2.026)\end{array}$ & $\begin{array}{l}42.87 * * * \\
(1.177)\end{array}$ & $\begin{array}{c}117.95 * * * \\
(3.560)\end{array}$ & $\begin{array}{l}57.13 * * * \\
(1.177)\end{array}$ & 43 \\
\hline Overall & $\begin{array}{l}47.34 * * * \\
(0.287)\end{array}$ & $\begin{array}{l}20.02 * * * \\
(0.186)\end{array}$ & $\begin{array}{l}45.38 * * * \\
(0.256)\end{array}$ & $\begin{array}{l}19.21 * * * \\
(0.176)\end{array}$ & $\begin{array}{l}92.72 * * * \\
(0.538)\end{array}$ & $\begin{array}{l}39.22 * * * \\
(0.360)\end{array}$ & $\begin{array}{c}154.31 * * * \\
(2.681)\end{array}$ & $\begin{array}{l}60.78 * * * \\
(0.360)\end{array}$ & 530 \\
\hline
\end{tabular}

Notes: The airline listed in a given row in the table is the ticketing carrier/downstream carrier for the integrated codeshare products used for computing the respective statistics in that row. Standard errors are in parentheses.

*** Significant at the 1 percent level.

** Significant at the 5 percent level.

* Significant at the 10 percent level.

profit, the equilibrium contract may not eliminate the upstream margin due to the upstream carrier's concern for the profitability of its own competing online product.

\section{B. Margins and Recovered Marginal Cost Estimates}

Summary statistics on price-cost margins and recovered marginal costs for integrated codeshare products are reported in Table 5. ${ }^{14}$ These statistics are broken down by ticketing carriers/downstream carriers of the integrated codeshare products, but the last row in the table reports overall summaries of these statistics across carriers. Note that all computed price-cost margins and recovered marginal cost estimates are statistically significant at conventional levels of statistical significance.

First, I focus on the last row in the table, which gives an overall picture of margins and recovered marginal costs. This row shows that mean margins for downstream and upstream carriers are $\$ 47.34$ and $\$ 45.38$, respectively, yielding a mean total margin (upstream plus downstream) of $\$ 92.72$. On average, total margin is 39.22 percent of final product price. The ratio of margin to price is referred to as

\footnotetext{
${ }^{14}$ Price-cost margins are computed using $\mathbf{m}_{d}^{1}(\mathbf{p} ; \hat{\alpha}, \hat{\boldsymbol{\beta}}, \hat{\boldsymbol{\sigma}})$ and $\mathbf{m}_{u}^{1}(\mathbf{p} ; \hat{\alpha}, \hat{\boldsymbol{\beta}}, \hat{\boldsymbol{\sigma}})$, while marginal costs are recovered using $\widehat{\mathbf{c}^{T}}=\mathbf{p}-\mathbf{m}_{d}^{1}(\mathbf{p} ; \hat{\alpha}, \hat{\boldsymbol{\beta}}, \hat{\boldsymbol{\sigma}})-\mathbf{m}_{u}^{1}(\mathbf{p} ; \hat{\alpha}, \hat{\boldsymbol{\beta}}, \hat{\boldsymbol{\sigma}})$. The parameter estimates, $\hat{\alpha}, \hat{\boldsymbol{\beta}}$, and $\hat{\boldsymbol{\sigma}}$ are set equal to their values reported in the first column of Table 3 .
} 
the Lerner Index. Therefore, the estimated Lerner Index for integrated codeshare products is approximately 0.39 . Considering all types of air travel products, Berry and Jia (2010) find Lerner Index estimates ranging from 0.41 to 0.60 , depending on model specification. As such, my Lerner Index estimates are within the "ballpark" of the estimates reported in Berry and Jia (2010).

Mean marginal cost is $\$ 154.31$. On average, marginal cost comprises 60.78 percent of final product price. With the mean itinerary distance for codeshare products in the sample being 2,369.46 miles, and mean marginal cost estimate being \$154.31, the implied marginal cost per mile is about 6 cents. This 6 cents marginal cost per mile estimate is exactly what Berry and Jia (2010) find using their econometric model. ${ }^{15}$ It is reassuring that the econometric model in this paper generates estimates that are consistent with previous research.

Now for comparing the computed price-cost margins and recovered marginal cost estimates across ticketing carriers/downstream carriers of the integrated codeshare products. First, as expected, Southwest Airlines being a formidable low-cost-carrier (LCC) offers products for sale with the lowest mean total margin (\$87.28), and by far the lowest mean marginal cost (\$117.95). Even though the products offered by Southwest have total margins as a percent of price being the highest ( 42.87 percent) compared to other carriers, as we will see in the next table, this is primarily driven by Southwest having the lowest mean price. It is noted that Southwest offers the least number of integrated codeshare products (43) compared to other carriers. This is not surprising however since strategic alliances between US domestic airlines are predominantly formed between the traditional network carriers rather than between LCCs.

By contrast, United Airlines and US Airways seem to offer products with the highest total margins, $\$ 94.97$ and $\$ 94.57$, respectively. Interestingly, these two carriers are alliance partners, so the vast majority of the codeshare products offered by each of them will have the other as the partner carrier. Not surprisingly, United Airlines, US Airways, and American Airlines, being traditional network carriers, offer products that have the highest marginal cost compared to products offered by other carriers.

\section{Counterfactual Simulations}

I now use the model to perform counterfactual simulations that reveal how equilibrium prices, number of passengers, and consumer welfare are affected if integrated codeshare products were efficiently priced. In other words, if I artificially eliminate the upstream margin for integrated codeshare products in the sample, what is the model's prediction of changes in equilibrium prices, number of passengers, and consumer surplus? ${ }^{16}$ The purpose of the simulations is to measure market effects relative to a scenario where double marginalization did not persist for these products. However, other alternate scenarios are possible and could be simulated and studied.

\footnotetext{
${ }^{15}$ See final paragraph on page 25 in Berry and Jia (2010). (2009).

${ }^{16}$ The counterfactual simulation procedure I outline below is similar in spirit to procedures in Villas-Boas
} 
First, I recover product-level marginal cost by rearranging the supply equation as follows:

$$
\widehat{\mathbf{c}^{T}}=\mathbf{p}-\mathbf{m}_{d}^{1}(\mathbf{p} ; \hat{\alpha}, \hat{\boldsymbol{\beta}}, \hat{\boldsymbol{\sigma}})-\mathbf{m}_{u}^{1}(\mathbf{p} ; \hat{\alpha}, \hat{\boldsymbol{\beta}}, \hat{\boldsymbol{\sigma}})
$$

where $\widehat{\mathbf{c}^{T}}$ is a vector containing estimates of aggregate marginal costs for supplying each product; $\mathbf{p}$ is a vector of actual prices from the dataset; while $\mathbf{m}_{d}^{1}(\cdot)$ and $\mathbf{m}_{u}^{1}(\cdot)$ are the respective downstream and upstream markup functions. In equation (17), all parameters $(\hat{\alpha}, \hat{\boldsymbol{\beta}}, \hat{\boldsymbol{\sigma}})$ are set equal to their estimated values in the first column of Table 3 . Using the previously recovered $\widehat{\mathbf{c}^{T}}$, I then solve the following counterfactual nonlinear supply equation for a new equilibrium price vector, $\mathbf{p}^{*}$, i.e., I compute the p* that satisfy

$$
\mathbf{p}^{*}-\widehat{\mathbf{c}^{T}}-\mathbf{m}_{d}^{1}\left(\mathbf{p}^{*} ; \hat{\alpha}, \hat{\boldsymbol{\beta}}, \hat{\boldsymbol{\sigma}}\right)=0
$$

A comparison of $\mathbf{p}$ with $\mathbf{p}^{*}$ reveals how equilibrium price would be affected if integrated codeshare products are efficiently priced.

It must be noted, however, that the counterfactual experiment outlined above assumes that when counterfactual supply equation (18) is used to characterize firms' optimal pricing behavior, the existing menu of products offered in a market stays the same. As stated previously, the empirical model in this paper assumes that firms' choice of whether to form a codeshare alliance is predetermined at the time of optimal price-setting behavior. In a more general model in which codeshare alliance formation is endogenous, it is possible that some firms may optimally choose not to form an alliance if policymakers could effectively enforce efficient pricing of integrated codeshare products. In other words, the equilibrium menu of products in the market if firms could be forced to behave according to equation (18) may be different than the equilibrium menu of products without such restrictions.

Another caveat of the counterfactual experiment worth pointing out lies in a strong assumption of the model that constant returns to scale can accurately approximate the production of air travel service over the range of passenger volumes observed in the data. The concern is as follows. In the event that the simulation exercise generate large predicted changes in passenger volumes, it is likely that constant returns to scale yields less accurate approximations of costs, which would therefore decrease the accuracy of simulated effects. Second, for simplicity the model abstracts from capacity constraints, but such constraints may be binding for some airlines, which would also decrease the accuracy of simulated effects.

Table 6 reports predicted percent changes in price and number of passengers of integrated codeshare products if upstream margin is eliminated from these products. The data in the table are reported by ticketing carrier of the codeshare products offered, as well as overall effects across carriers. Mean predicted percent changes are all statistically significant at conventional levels of statistical significance. I begin by focussing on the overall effects reported in the last row of the table.

Across all carriers and markets, the mean price of integrated codeshare products is $\$ 247.04$, while the mean number of passengers that use one of these products 
Table 6-Mean Initial Levels and Predicted Percent Changes in Price and Number of Passengers, by Airlines, of Integrated Codeshare Products if Upstream Margin Is Eliminated

\begin{tabular}{|c|c|c|c|c|c|}
\hline \multirow[b]{2}{*}{ Airline name } & \multicolumn{2}{|c|}{ Price } & \multicolumn{2}{|c|}{$\begin{array}{c}\text { Number of passengers } \\
\text { per product }\end{array}$} & \multirow[b]{2}{*}{$\begin{array}{c}\text { Number } \\
\text { of } \\
\text { products }\end{array}$} \\
\hline & $\begin{array}{c}\text { Mean } \\
\text { initial } \\
\text { levels } \\
(\$)\end{array}$ & $\begin{array}{c}\text { Mean } \\
\text { percent } \\
\text { change } \\
(\%)\end{array}$ & $\begin{array}{l}\text { Mean } \\
\text { initial } \\
\text { levels }\end{array}$ & $\begin{array}{c}\text { Mean } \\
\text { percent } \\
\text { change } \\
(\%)\end{array}$ & \\
\hline American Airlines Inc. & 263.35 & $\begin{array}{c}-18.47 * * * \\
(0.518)\end{array}$ & 21.33 & $\begin{array}{c}173.18 * * * \\
(0.712)\end{array}$ & 80 \\
\hline Alaska Airlines Inc. & 232.05 & $\begin{array}{c}-20.66^{* * * *} \\
(0.579)\end{array}$ & 23.40 & $\begin{array}{l}174.41 * * * \\
(1.131)\end{array}$ & 56 \\
\hline America West Airlines & 226.66 & $\begin{array}{c}-21.03 * * * \\
(0.375)\end{array}$ & 24.14 & $\begin{array}{l}173.80 * * * \\
(0.701)\end{array}$ & 95 \\
\hline United Air Lines Inc. & 250.16 & $\begin{array}{c}-20.30 * * * \\
(0.436)\end{array}$ & 17.55 & $\begin{array}{c}174.53 * * * \\
(0.618)\end{array}$ & 107 \\
\hline US Airways Inc. & 266.79 & $\begin{array}{c}-18.66^{* * * *} \\
(0.312)\end{array}$ & 21.38 & $\begin{array}{c}174.15^{* * * *} \\
(0.453)\end{array}$ & 149 \\
\hline Southwest Airlines & 205.23 & $\begin{array}{c}-21.87 * * * \\
(0.638)\end{array}$ & 47.75 & $\begin{array}{l}176.87 * * * \\
(0.758)\end{array}$ & 43 \\
\hline Overall & 247.04 & $\begin{array}{c}-19.86 * * * \\
(0.187)\end{array}$ & 23.45 & $\begin{array}{c}174.27 * * * \\
(0.279)\end{array}$ & 530 \\
\hline
\end{tabular}

Notes: The airline listed in a given row in the table is the ticketing carrier/downstream carrier for the integrated codeshare products used for computing the respective statistics in that row. Standard errors are in parentheses.

*** Significant at the 1 percent level.

** Significant at the 5 percent level.

* Significant at the 10 percent level.

during a quarter in an origin-destination market is 23.45. Efficient pricing of these products will result in a fall in their prices by a mean 19.86 percent, but a far more substantial mean increase of 174.27 percent in the number of passengers that use a typical integrated codeshare product in an origin-destination market during a quarter.

Now for comparing across airlines. We see that Southwest Airlines has the lowest mean price $(\$ 205.23)$, as well as the largest mean predicted percent reduction in the price of its integrated codeshare products $(-21.87$ percent). In addition, even though Southwest offers the fewest number of integrated codeshare products (43), this carrier has the largest mean number of passengers (47.75) traveling on its typical integrated codeshare product, and is predicted to experience the largest percent increase in the number of its passengers on these products (176.87 percent) if the products did not have double markup. By contrast, American Airlines and US Airways offer the most expensive integrated codeshare products, mean price of $\$ 263.35$ and $\$ 266.79$, respectively, and are predicted to experience the smallest mean percent declines in prices of these products, -18.47 percent and -18.66 percent, respectively.

Further analysis reveals that predicted percent changes in price and number of passengers do not vary much by market nonstop flight distance or market origin city population (a measure of market size). 
Next, I explore the extent to which consumer welfare is affected by the pricequantity changes that are associated with efficient pricing of integrated codeshare products.

In the case of the logit model, a measure of consumer surplus for consumer $i$ is given by ( see Nevo 2000b; McFadden 1981; Small and Rosen 1981; Train 2003)

$$
C S_{i}=\frac{1}{\alpha_{i}} \ln \left[\sum_{j=0}^{J} e^{V_{i j}}\right]
$$

where $\alpha_{i}$ is the random coefficient on price in equation (1) and $V_{i j}=\delta_{j t}+\mu_{i j t}$ from equation (2). Therefore, a measure of the change in consumer surplus for consumer $i$ due to efficient pricing of integrated codeshare products is given by

$$
\Delta C S_{i}=\frac{\ln \left[\sum_{j=0}^{J} e^{V_{i j}^{*}}\right]-\ln \left[\sum_{j=0}^{J} e^{V_{i j}}\right]}{\alpha_{i}},
$$

where $V_{i j}^{*}$ and $V_{i j}$ are evaluated at $\mathbf{p}^{*}$ and $\mathbf{p}$, respectively. The change in expected consumer surplus for an entire origin-destination market is given by

$$
T C S=M \int \Delta C S_{i} d F(\nu)
$$

where $M$ is the size of the origin city population, and $F(\cdot)$ is the standard normal distribution function as previously defined.

My analyses reveal that, over the course of a year, the mean level of consumer surplus for an origin-destination market is $\$ 498,026$, but efficient pricing of integrated codeshare products in these markets is predicted to increase consumer surplus by a mean 7.37 percent. The largest predicted percent increase in annual consumer surplus is a mean 11.69 percent across origin-destination markets that have origin city population equal to or less than 362,470 people. However, compared to other markets, these markets have the lowest mean level of consumer surplus, $\$ 294,756.40$. Markets with origin city population larger than 1,223,400 people have the second largest predicted percent increase, a mean 7.99 percent, but unlike small population markets, large population markets have relatively large mean consumer surplus of $\$ 494,821.10$.

Markets with nonstop flight distance equal to or less than 1,754 miles have the largest mean level consumer surplus of $\$ 913,597.50$, but these markets are predicted to have the smallest mean percent increase in consumer surplus, 2.69 percent. Markets with nonstop flight distances between 1,754 and 2,412 miles are predicted to have the largest percent increases in consumer surplus (approximately 9 percent). However, the level of consumer surplus in these markets is relatively small, typically below \$370,000. 


\section{Conclusion}

Using a structural econometric model, this paper investigates whether the upstream markup of integrated codeshare products is eliminated when codeshare partners optimally price these products. I define integrated codeshare products as traditional codeshare products for which the pure operating carrier also offers its own competing online product in the said market. The econometric estimates suggest that the upstream markup is not eliminated for these products. This result is consistent with theoretical predictions in Chen and Gayle (2007), and also has links to the literature on vertical integration. An intuitive explanation that the theoretical literature suggest is that the strategic incentives of an upstream/pure operating carrier of a traditional codeshare product, that also offers its own online product in the said market (integrated upstream carrier), is likely to differ from an upstream carrier that does not offer its own competing online product (unintegrated upstream carrier). Specifically, the integrated upstream carrier optimally chooses not to eliminate its margin for its codeshare products. A reason for such strategic behavior by the integrated upstream carrier is that by raising the price of its trip segment (the intermediate good price), this carrier is able to reduce the intensity of downstream competition for its own online product.

I also use the estimated model to perform counterfactual simulations that reveal how equilibrium prices, air travel demand, and consumer welfare are affected if integrated codeshare products were efficiently priced. I find that eliminating the upstream margin of integrated codeshare products results in a fall in prices of these products by a mean 19.86 percent. In addition, consumer surplus is predicted to increase by a mean 7.37 percent for an origin-destination market.

As this paper only constitutes a first attempt at an explicit empirical analysis of the vertical aspects of airline codesharing, there are several ways in which future research may build upon the model and the issues explored in this paper. For example, the supply side of the model in its current form is unable to handle air travel products that have a subset of their trip segments codeshared, while the other segments are operated by unaffiliated carriers. Second, the model in its current form does not capture products that have each trip segment operated and marketed by unaffiliated carriers. Modifying the supply model to capture these types of products may prove useful if the model is used to study international air travel markets where these products are more popular. Thus, another possible extension to this research is to use the model to study international air travel markets where codeshare partners are distinct national carriers and less likely to offer competing online services in the said market. 


\section{Appendix A: AdDitional Tables}

Table A1-List of Airlines in the Sample and the Types of Products In the SAmple They Are InVolved IN

\begin{tabular}{lcc}
\hline \hline Airline name & Airline code & $\begin{array}{c}\text { Types of products in the sample airline } \\
\text { is involved in }\end{array}$ \\
\hline American Airlines Inc. & AA & Online and traditional codeshare \\
Alaska Airlines Inc. & AS & Online and traditional codeshare \\
JetBlue Airways & B6 & Online only \\
Continental Air Lines Inc. & CO & Online only \\
Delta Air Lines Inc. & DL & Online only \\
Frontier Airlines & F9 & Online only \\
AirTran Airways & FL & Online and traditional codeshare \\
America West Airlines & HP & Online only \\
Spirit Air Lines & NK & Online only \\
Northwest Airlines Inc. & NW & Online and traditional codeshare \\
ATA Airlines & TZ & Online only \\
USA 3000 Airlines & U5 & Online and traditional codeshare \\
United Air Lines Inc. & UA & Online and traditional codeshare \\
US Airways Inc. & US & Online and traditional codeshare \\
Southwest Airlines & WN & Online only \\
Midwest Airline & YX & \\
\hline
\end{tabular}

Table A2-List of Cities, States and Corresponding Airports in the Data Sample

\begin{tabular}{lclc}
\hline \hline City, state & Airport code & City, state & Airport code \\
\hline Austin, TX & AUS & Portland, OR & PDX \\
Boston, MA & BOS & Philadelphia, PA & PHL \\
Charlotte, NC & CLT & Phoenix, AZ & PHX \\
Washington, DC & DCA & Pittsburgh, PA & PIT \\
Denver, CO & DEN & Raleigh/Durham, NC & RDU \\
Dallas, TX & DFW & Reno, NV & RNO \\
Fort Lauderdale, FL & FLL & Fort Myers, FL & RSW \\
New York City & JFK & San Diego, CA & SAN \\
Las Vegas, NV & LAS & Seattle, WA & SEA \\
Los Angeles, CA & LAX & San Francisco, CA & SFO \\
New York City & LGA & San Jose, CA & SJC \\
Miami, FL & MIA & Santa Ana, CA & SNA \\
Chicago, IL & ORD & St. Louis, MO & STL \\
\hline
\end{tabular}

\section{APPENDix B: DeRiVATION OF $\Delta_{f}$}

Note that $\Delta_{f}=\Delta_{p}^{\prime} \Delta_{r}$. We already know how to compute $\Delta_{r}$, where an element in $\Delta_{r}$ is given by $\Delta_{r}(k, j)=\frac{\partial d_{j}}{\partial p_{k}}$. Therefore, to obtain $\Delta_{f}$, the only additional computation needed is $\Delta_{p}$.

Let $\Delta_{p}$ be a matrix of derivatives of all final prices with respect to upstream prices. In other words, $\Delta_{p}$ tells an upstream carrier how all downstream final prices change given a change in the price for its pure operating services. Thus, an element in $\Delta_{p}$ is given by $\Delta_{p}(k, j)=\frac{\partial p_{j}}{\partial s_{k}^{f}}$. 
Identical to the derivation process outlined in supplements to Villas-Boas (2007), I start with a first-order condition for a downstream firm. The downstream first-order condition for a codeshare product is given by

$$
d_{j}(\mathbf{p})+\sum_{k \in \mathcal{F}_{r}}\left(p_{k}-s_{k}^{f}-c_{k}^{r}\right) \frac{\partial d_{k}(\mathbf{p})}{\partial p_{j}}=0 .
$$

If we totally differentiate equation (21) with respect to all final prices and an upstream price, $s_{n}^{f}$, then

$$
\begin{aligned}
\sum_{k=1}^{J}\left\{\frac{\partial d_{j}}{\partial p_{k}}+\sum_{m=1}^{J}\left[\Omega_{r}(m, j) \frac{\partial^{2} d_{m}}{\partial p_{j} \partial p_{k}}\left(p_{m}-s_{m}^{f}-c_{m}^{r}\right)\right]+\Omega_{r}(k, j) \frac{\partial d_{k}}{\partial p_{j}}\right\} \mathbf{d} p_{k} \\
-\Omega_{r}(n, j) \frac{\partial d_{n}}{\partial p_{j}} \mathbf{d} s_{n}^{f}=0,
\end{aligned}
$$

where $k, j, m$, and $n$ are all indexing products. Let $G$ be a $J \times J$ matrix with elements $g(j, k)$, where $g(j, k)=\left\{\frac{\partial d_{j}}{\partial p_{k}}+\sum_{m=1}^{J}\left[\Omega_{r}(m, j) \frac{\partial^{2} d_{m}}{\partial p_{j} \partial p_{k}}\left(p_{m}-s_{m}^{f}-c_{m}^{r}\right)\right]+\right.$ $\left.\Omega_{r}(k, j) \frac{\partial d_{k}}{\partial p_{j}}\right\}$. Note that matrix $\mathbf{G}$ requires computing second-order derivatives of the demand function, $\frac{\partial^{2} d_{m}}{\partial p_{j} \partial p_{k}}$. Since $\left(p_{m}-s_{m}^{f}-c_{m}^{r}\right)$ can be expressed exclusively in terms of demand parameters (see equation (4)), matrix $\mathbf{G}$ does not require information on upstream prices or marginal costs.

Let $\mathbf{H}_{n}$ be a $J$-dimensional column vector with elements $h(j, n)$, where $h(j, n)$ $=\Omega_{r}(n, j) \frac{\partial d_{n}}{\partial p_{j}}$. For a given upstream price $s_{n}^{f}$, equation (22) is computed for each of the $J$ products. Given the above definitions for $\mathbf{G}$ and $\mathbf{H}_{n}$, these $J$ equations can be compactly represented by

$$
\mathbf{G} \mathbf{d} p-\mathbf{H}_{n} \mathbf{d} s_{n}^{f}=\mathbf{0}
$$

or

$$
\frac{\mathbf{d} p}{\mathbf{d} s_{n}^{f}}=\mathbf{G}^{-1} \mathbf{H}_{n}
$$

$\frac{\mathbf{d} p}{\mathbf{d} s_{n}^{f}}$ is a $J \times 1$ derivative vector, where the $j$ th element tells us how the final price of product $j$ changes as a result of a change in the upstream price of product $n$. The $J \times J$ matrix, $\Delta_{p}$, is obtained by stacking all $J$ derivative vectors (one for each product $n), \frac{\mathbf{d} p}{\mathbf{d} s_{n}^{f}}$, together. 


\section{Appendix C. Estimation Details}

The GMM parameter estimates can be obtained by solving the following problem:

$$
\operatorname{Min}_{\alpha, \beta, \sigma, \gamma} \eta^{\prime} \mathbf{Z} \Phi^{-1} \mathbf{Z}^{\prime} \eta
$$

where $\boldsymbol{\eta}=\left(\begin{array}{l}\xi \\ \psi\end{array}\right)$ is a vector of demand $(\boldsymbol{\xi})$ and supply $(\boldsymbol{\psi})$ residuals; $\mathbf{Z}$ is a block diagonal matrix of instruments for the demand and supply equations; and $\Phi^{-1}$ is a positive definite weight matrix. Matrix $\mathbf{Z}$ is specified as: $\mathbf{Z}=\left(\begin{array}{cc}\mathbf{Z}_{d} & \mathbf{0} \\ \mathbf{0} & \mathbf{Z}_{s}\end{array}\right)$, where $\mathbf{Z}_{d}$ are instruments for the demand equation, and $\mathbf{Z}_{s}$ are instruments for the supply equation. The weight matrix $\Phi^{-1}$ is specified as: $\Phi^{-1}=\left(\begin{array}{cc}{\left[\frac{1}{n} \mathbf{Z}_{d}^{\prime} \xi \xi^{\prime} \mathbf{Z}_{d}\right]^{-1}} & \mathbf{0} \\ \mathbf{0} & {\left[\frac{1}{n} \mathbf{Z}_{s}^{\prime} \psi \psi^{\prime} \mathbf{Z}_{s}\right]^{-1}}\end{array}\right)$.

The GMM optimization process in (24) can be made less burdensome if we exploit the fact that $\alpha, \boldsymbol{\beta}$, and $\gamma$ enter the GMM objective function linearly. In particular, there exist closed-form expressions for the values of $\alpha, \beta$, and $\gamma$ that minimize the objective function. Specifically,

$$
\left(\begin{array}{l}
\alpha \\
\beta
\end{array}\right)=\left(\mathbf{X}_{d}^{\prime} \mathbf{Z}_{d} \Phi_{d}^{-1} \mathbf{Z}_{d}^{\prime} \mathbf{X}_{d}\right)^{-1} \mathbf{X}_{d}^{\prime} \mathbf{Z}_{d} \Phi_{d}^{-1} \mathbf{Z}_{d}^{\prime} \delta
$$

and

$$
\boldsymbol{\gamma}=\left(\mathbf{W}^{\prime} \mathbf{Z}_{s} \Phi_{s}^{-1} \mathbf{Z}_{s}^{\prime} \mathbf{W}\right)^{-1} \mathbf{W}^{\prime} \mathbf{Z}_{s} \Phi_{s}^{-1} \mathbf{Z}_{s}^{\prime} \mathbf{Y}
$$

where $\mathbf{X}_{d}$ is a matrix of regressors in the demand model $\left(p_{j t}\right.$ and $\left.\mathbf{x}_{j t}\right) ; \mathbf{Z}_{d}$ is a matrix of demand instruments; $\boldsymbol{\Phi}_{d}^{-1}$ is the portion of $\boldsymbol{\Phi}^{-1}$ that corresponds to demand moment conditions; $\delta$ is a vector of mean utilities for the products; $\mathbf{W}$ is the matrix of marginal cost shifters in the supply model; $\boldsymbol{\Phi}_{s}^{-1}$ is the portion of $\boldsymbol{\Phi}^{-1}$ that corresponds to supply moment conditions; $\mathbf{Z}_{s}$ is a matrix of supply instruments; and vector $\mathbf{Y}=\ln \left[\mathbf{p}-\mathbf{m}_{d}^{1}-\mathbf{m}_{u}^{1}\right]$ comes from the supply equation (equation (12)). In the case of supply Model 2, Model 3, and Model 4, $\mathbf{Y}=\ln \left[\mathbf{p}-\mathbf{m}_{d}^{2}-\mathbf{m}_{u}^{2}\right]$, $\mathbf{Y}=\ln \left[\mathbf{p}-\mathbf{m}_{d}^{3}\right]$, and $\mathbf{Y}=\ln \left[\mathbf{p}-\mathbf{m}_{d}^{4}-\mathbf{m}_{u}^{4}\right]$, respectively.

To recover the vector of mean utilities, $\delta$, I exploit the estimation strategy that demand parameters must be chosen such that observed product shares are equal to predicted product shares, i.e.,

$$
D_{j t}=d_{j t}(\boldsymbol{\delta} ; \boldsymbol{\sigma}) \text { for all } j \text { and } t .
$$

Let an initial set of values for the taste variation parameters in $\sigma$ be denoted as $\sigma_{(0)}$. Given $\boldsymbol{\sigma}_{(0)}$, we can numerically solve the system of equations in (27) for the corresponding vector of mean utility values, $\boldsymbol{\delta}_{(0)}$. With $\boldsymbol{\delta}_{(0)}$ in hand, we can recover the associated values of $\alpha_{(0)}$ and $\boldsymbol{\beta}_{(0)}$ using (25), and compute the corresponding product margin values, $\mathbf{m}_{d,(0)}^{1}$ and $\mathbf{m}_{u,(0)}^{1}$. In addition, with $\mathbf{m}_{d,(0)}^{1}$ and $\mathbf{m}_{u,(0)}^{1}$ in hand, we can compute vector $\mathbf{Y}_{(0)}$ and therefore recover the associated $\gamma_{(0)}$ via equation (26). 
The demand and supply residuals are computed using, $\xi_{j t}(0)=\delta_{j t(0)}-\left(\mathbf{x}_{j t} \boldsymbol{\beta}_{(0)}+\alpha_{(0)} p_{j t}\right)$ and $\psi_{j t(0)}=\ln \left[p_{j t}-m_{d j t(0)}^{1}-m_{u j t(0)}^{1}\right]-\mathbf{W}_{j t} \gamma(0)$, respectively.

In summary, once the closed-form expressions in (25) and (26) are substituted into the objective function, we can effectively perform the minimization search algorithm just over $\sigma$. In other words, the optimization in (24) effectively becomes

$$
\operatorname{Min}_{\sigma} \eta^{\prime} \mathbf{Z} \Phi^{-1} \mathbf{Z}^{\prime} \eta
$$

Once the optimal $\hat{\boldsymbol{\sigma}}$ is found, then the associated parameter estimates $\hat{\alpha}, \hat{\boldsymbol{\beta}}$, and $\hat{\gamma}$ are recovered using equations (25), (26), and (27).

\section{REFERENCES}

Aguirregabiria, Victor, and Chun-Yu Ho. 2012. "A Dynamic Oligopoly Game of the US Airline Industry: Estimation and Policy Experiments." Journal of Econometrics 168 (1): 156-73.

-Armantier, Olivier, and Oliver Richard. 2008. "Domestic Airline Alliances and Consumer Welfare." RAND Journal of Economics 39 (3): 875-904.

- Bamberger, Gustavo E., Dennis W. Carlton, and Lynette R. Neumann. 2004. "An Empirical Investigation of the Competitive Effects of Domestic Airline Alliances." Journal of Law \& Economics 47 (1): 195-222.

Berry, Steven T. 1990. “Airport Presence as Product Differentiation.” American Economic Review 80 (2): 394-99.

- Berry, Steven T. 1992. "Estimation of a Model of Entry in the Airline Industry." Econometrica 60 (4): 889-917.

- Berry, Steven T. 1994. "Estimating Discrete-Choice Models of Product Differentiation." RAND Journal of Economics 25 (2): 242-62.

Berry, Steven, Michael Carnall, and Pablo T. Spiller. 2006. "Airline Hubs: Costs, Markups and the Implications of Customer Heterogeneity." In Competition Policy and Anti-Trust. Vol. 1, Advances in Airline Economics, edited by Darin Lee, 183-214. Bingley: Emerald Group Publishing Limited.

- Berry, Steven, and Panle Jia. 2010. "Tracing the Woes: An Empirical Analysis of the Airline Industry." American Economic Journal: Microeconomics 2 (3): 1-43.

- Berry, Steven, James Levinsohn, and Ariel Pakes. 1995. "Automobile Prices in Market Equilibrium." Econometrica 63 (4): 841-90.

Bonnet, Céline, and Pierre Dubois. 2010. "Inference on Vertical Contracts between Manufacturers and Retailers Allowing for Nonlinear Pricing and Resale Price Maintenance." RAND Journal of Economics 41 (1): 139-64.

Bonnet, Céline, Pierre Dubois, and Michel Simioni. 2006. "Two-Part Tariffs versus Linear Pricing Between Manufacturers and Retailers: Empirical Tests on Differentiated Products Markets." CEPR Discussion Papers 6016.

Bonnet, Céline, Pierre Dubois, and Sofia B. Villas-Boas. Forthcoming. "Empirical Evidence on the Role of Non Linear Wholesale Pricing and Vertical Restraints on Cost Pass-Through." Review of Economics and Statistics.

Borenstein, Severin. 1989. "Hubs and High Fares: Dominance and Market Power in the U.S. Airline Industry." RAND Journal of Economics 20 (3): 344-65.

-Borenstein, Severin. 1991. "The Dominant-Firm Advantage in Multiproduct Industries: Evidence from U.S. Airlines." Quarterly Journal of Economics 106 (4): 1237-66.

Brueckner, Jan K. 2001. "The Economics of International Codesharing: An Analysis of Airline Alliances." International Journal of Industrial Organization 19 (10): 1475-98.

Brueckner, Jan K. 2003. "International Airfares in the Age of Alliances: The Effects of Codesharing and Antitrust Immunity." Review of Economics and Statistics 85 (1): 105-18.

- Brueckner, Jan K., Darin N. Lee, and Ethan S. Singer. 2011. "Alliances, Codesharing, Antitrust Immunity, and International Airfares: Do Previous Patterns Persist?" Journal of Competition Law \& Economics 7 (3): 573-602.

Brueckner, Jan K., and Stef Proost. 2010. "Carve-Outs under Airline Antitrust Immunity." International Journal of Industrial Organization 28 (6): 657-68. 
- Brueckner, Jan K., and W. Tom Whalen. 2000. "The Price Effects of International Airline Alliances." Journal of Law and Economics 43 (2): 503-46.

-Chen, Yongmin. 2001. "On Vertical Mergers and Their Competitive Effects." RAND Journal of Economics 32 (4): 667-85.

-Chen, Yongmin, and Philip G. Gayle. 2007. "Vertical Contracting Between Airlines: An Equilibrium Analysis of Codeshare Alliances." International Journal of Industrial Organization 25 (5): 1046-60.

Evans, William N., and Ioannis N. Kessides. 1993. "Localized Market Power in the U.S. Airline Industry." Review of Economics and Statistics 75 (1): 66-75.

-Forbes, Silke Januszewski, and Mara Lederman. 2009. "Adaptation and Vertical Integration in the Airline Industry." American Economic Review 99 (5): 1831-49.

-Forbes, Silke J., and Mara Lederman. 2010. "Does Vertical Integration Affect Firm Performance? Evidence from the Airline Industry." RAND Journal of Economics 41 (4): 765-90.

-Forbes, Silke J., and Mara Lederman. 2013. "Contract Form and Technology Adoption in a Network Industry." Journal of Law, Economics, \& Organization 29 (2): 385-413.

- Gayle, Philip G. 2007a. "Airline Code-Share Alliances and Their Competitive Effects." Journal of Law \& Economics 50 (4): 781-819.

-Gayle, Philip G. 2007b. "Is Virtual Codesharing a Market Segmenting Mechanism Employed by Airlines?" Economics Letters 95 (1): 17-24.

-Gayle, Philip G. 2008. "An Empirical Analysis of the Competitive Effects of the Delta/Continental/ Northwest Code-Share Alliance." Journal of Law \& Economics 51 (4): 743-66.

Gayle, Philip G., and Xin Xie. 2012. "Entry Deterrence and Strategic Alliances: Evidence from a Dynamic Structural Econometric Model.” http://www.colorado.edu/econ/seminars/Gayle_Xie.pdf.

Gayle, Philip G. 2013. "On the Efficiency of Codeshare Contracts between Airlines: Is Double Marginalization Eliminated?: Dataset." American Economics Journal: Microeconomics. http://dx.doi. org/10.1257/mic.5.4.244.

Goldberg, Pinelopi Koujianou, and Frank Verboven. 2001. "The Evolution of Price Dispersion in the European Car Market." Review of Economic Studies 68 (4): 811-48.

-Hastings, Justine S., and Richard J. Gilbert. 2005. "Market Power, Vertical Integration and the Wholesale Price of Gasoline." Journal of Industrial Economics 53 (4): 469-92.

-Ito, Harumi, and Darin Lee. 2007. "Domestic Code Sharing, Alliances, and Airfares in the U.S. Airline Industry." Journal of Law and Economics 50 (2): 355-80.

Lederman, Mara. 2007. "Do Enhancements to Loyalty Programs affect Demand? The Impact of International Frequent Flyer Partnerships on Domestic Airline Demand." RAND Journal of Economics 38 (4): 1134-58.

McFadden, Daniel. 1981. "Structural Discrete Probability Models Derived from Theories of Choice." In Structural Analysis of Discrete Data and Econometric Applications, edited by Charles F. Manski and Daniel L. McFadden, 198-271. Cambridge, MA: MIT Press.

Nevo, Aviv. 2000a. "A Practitioner's Guide to Estimation of Random-Coefficients Logit Models of Demand." Journal of Economics \& Management Strategy 9 (4): 513-48.

-Nevo, Aviv. 2000b. "Mergers with differentiated products: the case of the ready-to-eat cereal industry." RAND Journal of Economics 31 (3): 395-421.

Peters, Craig. 2006. "Evaluating the Performance of Merger Simulation: Evidence from the U.S. Airline Industry." Journal of Law and Economics 49 (2): 627-49.

- Rivers, Douglas, and Quang Vuong. 2002. "Model Selection Tests for Nonlinear Dynamic Models." Econometrics Journal 5 (1): 1-39.

-Small, Kenneth A., and Harvey S. Rosen. 1981. "Applied Welfare Economics with Discrete Choice Models." Econometrica 49 (1): 105-30.

-Smith, Richard J. 1992. "Non-Nested Tests for Competing Models Estimated by Generalized Method of Moments." Econometrica 60 (4): 973-80.

Train, Kenneth. 2003. Discrete Choice Methods with Simulation. New York: Cambridge University Press.

-Villas-Boas, Sofia Berto. 2007. "Vertical Relationships between Manufacturers and Retailers: Inference with Limited Data." Review of Economic Studies 74 (2): 625-52.

-Villas-Boas, Sofia Berto. 2009. "An Empirical Investigation of the Welfare Effects of Banning Wholesale Price Discrimination." RAND Journal of Economics 40 (1): 20-46. 